\title{
La cruz, el sacrificio y la ornamentación cristiano-indígena. Luces sobre un taller de alfarería de mediados del siglo XVI en el valle de México
}

\section{The Cross, the Sacrifice, and Native Christian Ornament. A Glimpse into a mid Sixteenth-Century Pottery Workshop in the Valley of Mexico}

Artículo recibido el 4 de diciembre de 2017; devuelto para revisión el 16 de enero de 20I8; aceptado el I6 de abril de 20I8, http://dx.doi.org/Io.2220I/iie.18703062e.20I8

Pablo Escalante Gonzalbo Instituto de Investigaciones Estéticas, UNAM

Líneas de investigación Arte cristiano-indígena de la Nueva España; arte y liturgia en los pueblos de indios; transformación colonial de los códices; cultura popular y vida cotidiana.

Research lines Christian-Native art in New Spain; liturgy and art at the "Pueblos de indios"; colonial transformation of the codices; popular culture and everyday life.

Publicaciones más relevantes "El término sincretismo y el estudio del arte novohispano del siglo xv", en Nombrar y explicar. La terminología en el estudio del arte ibérico y latinoamericano, ed. Patricia Díaz Cayeros, Montserrat Galí I Boadella y Peter Krieger (Ciudad de México: Universidad Nacional Autónoma de México-Instituto de Investigaciones Estéticas, 2012), 305-320; Los códices mesoamericanos antes y después de la Conquista. Historia de un lenguaje pictográfico (Ciudad de México: Fondo de Cultura Económica, 20IO); El arte cristiano-indígena del siglo XVI novohispano y sus modelos europeos (Ciudad de México: Centro de Investigación y Docencia en Humanidades del Estado de Morelos, 2008); "Fulgor y muerte de Juan Gerson o Las oscilaciones de los pintores de Tecamachalco", en XXVI Coloquio Internacional de Historia del Arte. El proceso creativo (Ciudad de México: Universidad Nacional Autónoma de México-Instituto de Investigaciones Estéticas, 2006): 325-342; "Cristo, su sangre y los indios. Exploraciones iconográficas sobre el arte mexicano del siglo xvi", en Herencias indigenas, tradicones europeas y la mirada europea, ed. Helga von Kügelgen (Fráncfort del Meno: Vervuert, 2002), 7I-93.

Resumen Este trabajo parte del análisis de una pieza circular de cerámica con símbolos indígenas y cristianos procedente de Teotihuacán y recupera- 
da a finales del siglo XIx. Tras un cotejo con otras piezas —entre ellas, otros tres discos, hasta ahora inéditos - se argumenta la pertenencia de todo el conjunto a un taller de alfarería, probablemente ligado a la escuela de artes y oficios de los franciscanos. Se trata de la mayor muestra de alfarería litúrgica cristiano-indígena del siglo XvI.

Palabras clave Sincretismo; Arte cristiano-indígena; Alfarería; Nahuas; San Juan Teotihuacán.

Abstract This work is based on the analysis of a circular ceramic piece with indigenous and Christian symbols from Teotihuacán, recovered at the end of the 19th century. After a comparison with other pieces - among them, three other discs, hitherto unpublished - the whole group is shown to belong to a pottery workshop probably linked to the arts and crafts school of the Franciscans. It is the largest sample of sixteenth-century indigenous Christian liturgical pottery.

Keywords Syncretism; Native-Christian art; Pottery; Nahua; San Juan Teotihuacán. 
DOI: http://dx.doi.org/10.22201/iie.18703062e.2018.113.2659

PABLO ESCALANTE GONZALBO

INSTITUTO DE INVESTIGACIONES ESTÉTICAS, UNAM

\section{La cruz, el sacrificio y la ornamentación cristiano-indígena Luces sobre un taller de alfarería de mediados del siglo XVI en el valle de México}

$\mathrm{E}$ n el año I900 se publicó la fotografía de una pieza de cerámica de forma circular (fig. I $)^{\mathrm{I}}$ que tiene un interés muy grande para el estudio de la iconografía novohispana de las primeras décadas y, en general, para el conocimiento de lo que llamamos arte cristiano-indígena. ${ }^{2}$ El disco de cerámica volvió a publicarse muchos años después, en 1992, con motivo de una exposición en el Mexican Fine Arts Center Museum de Chicago, ${ }^{3}$ cuando se exhibió por primera vez. Se trata de una pieza especialmente interesante debido a su antigüedad, a que representa uno de los escasos ejemplos de obras cristianoindígenas en cerámica, y a su iconografía que, provisionalmente, podríamos

I. Antonio Peñafiel, Teotihuacán. Estudio histórico y arqueológico (Ciudad de México: Oficina Tipográfica de la Secretaría de Fomento, 1900), 74.

2. Al final de este artículo se presenta una discusión más amplia sobre el concepto y el campo de estudio. El término fue utilizado por primera vez por Manuel Toussaint en I948. Se refería a la pintura, en particular, y establecía en su argumentación la fuerte diferencia de las dos tradiciones. Su uso de ambos términos, cristiano e indígena, separados/unidos por un guión pone de manifiesto la yuxtaposición característica de estas manifestaciones. Manuel Toussaint, Arte colonial en México, 4a ed. (Ciudad de México: Universidad Nacional Autónoma de México, I983), I7.

3. Carlos Tortolero, ed., México. La visión del cosmos. Three Thousand Years of Creativity (Chicago: The Mexican Fine Arts Center Museum, 1992), 3. 


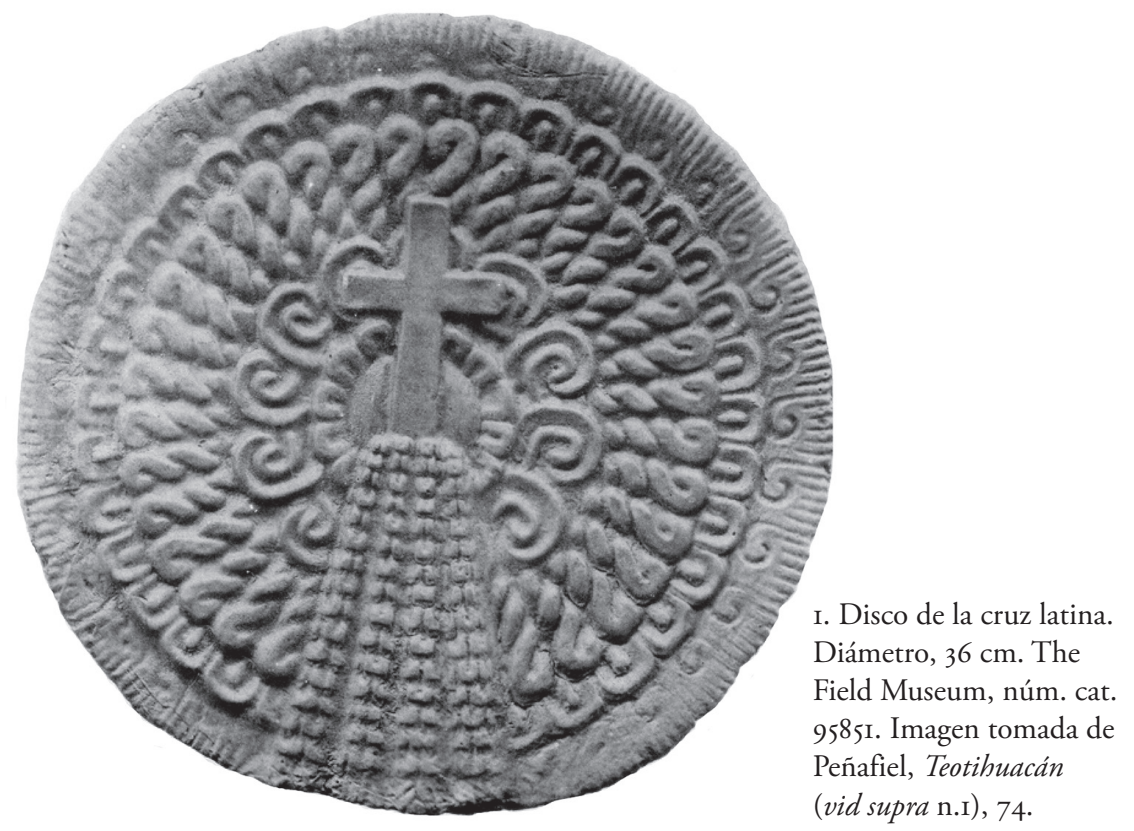

llamar mixta. La pieza forma parte de la colección Peñafiel, vendida por Frederick Starr al Field Museum de Chicago. ${ }^{4}$

El disco tiene un diámetro de $36 \mathrm{~cm}$, un espesor de $3.2 \mathrm{~cm}$ y un peso de $4.076 \mathrm{~kg}$. Sólo tiene imágenes en el frente, su reverso carece de cualquier representación. La pieza se quebró tras su hallazgo y fue reparada, pero no muestra huellas considerables de desgaste en época anterior, tampoco tiene las fracturas en los bordes o los restos de mezcla que cabría esperar si la pieza hubiera estado originalmente pegada a una superficie arquitectónica. La superposición de los diseños y la ausencia de huellas de pastillaje indican que la pieza se realizó con un molde. Otros datos sobre el contexto reconstruido de la pieza confirman sin lugar a dudas el uso del molde. ${ }^{5} \mathrm{Al}$ parecer, la pieza no llegó a

4. Más adelante se presentan algunos datos sobre esta venta. La colección no cuenta aún con un catálogo. Sólo existe la base de datos del museo. Agradezco al Field Museum y en particular a Gary Feinman, Chris Philipp, Cassie Pontone y Julia Kennedy por la ayuda que me han dado y continúan dándome en el estudio de esta y otras piezas de la colección.

5. Como se verá, el disco forma parte de un conjunto de piezas trabajadas en un taller que produjo una gran cantidad de moldes. De hecho, de otras tres piezas circulares del mismo contexto relacionadas con este disco, dos son moldes. 
utilizarse en la época de su producción. Su destino original habría sido formar parte de una especie de mosaico decorativo de objetos de cerámica en la fachada de alguna capilla.

\section{La herida y la cruz}

Dos conjuntos de diseños forman la decoración del disco: uno se despliega en forma radial a partir del centro y otro asciende verticalmente desde la base hacia el punto central y se le superpone. En general, los diseños circulares coinciden con motivos de la tradición mesoamericana aunque no se encuentra una combinación idéntica en ninguna obra prehispánica. En el núcleo se advierte la representación de una flor cuyo centro es grande como el capítulo de un girasol, en contraste con sus pétalos cortos. Si observamos los diseños que rodean la flor y se suceden hacia el exterior del círculo podemos ver un motivo de ganchos reiterados, como ondas que se encrestan, que coincide con representaciones mesoamericanas de líquido en movimiento (fig. 2a). ${ }^{6}$ Luego vemos una progresión de bandas que se doblan sobre sí mismas formando torzales. El torzal aparece con alguna frecuencia en imágenes cosmográficas mesoamericanas y representa las rutas o conductos de naturaleza opuesta que permitían descender a las fuerzas celestes y ascender a las fuerzas del inframundo (fig. 2b). ${ }^{7}$ Las dos últimas franjas están formadas por motivos plumarios: el primero es la representación

6. Códice Borgia (México: Fondo de Cultura Económica, I963), lám. 20, zona inferior izquierda. Los ganchos sucesivos aparecen también en representaciones más antiguas; se utilizaron, por ejemplo, para marcar el cuello de los personajes representados en las escenas alusivas del juego de pelota de Dainzú, en Oaxaca. También encontramos el diseño en la falda de la gran escultura conocida como Chalchiuhtlicue, en Teotihuacán, y en otras imágenes. Seler describe el cuerpo de líquido de superficie ondulante como "agua sagrada-sangre". Eduard Seler, en sus comentarios al Códice Borgia, vol. I, lám. 20. Sobre la interpretación sacrificial de las imágenes de Dainzú, véase Heather S. Orr, "Procession Rituals and Shrine Sites: The Politics of Sacred Space In the Late Formative Valley of Oaxaca", en Landscape and Power in Ancient Mesoameircia, eds. Rex Koontz, Kathryn Reese-Taylor y Annabeth Headrick (Boulder, Colorado: Westview Press, 200I), 67-7I.

7. Alfredo López Austin, Cuerpo humano e ideología, vol. I (Ciudad de México: Universidad Nacional Autónoma de México, 1984), 66-67. Puede observarse el diseño de las bandas, por ejemplo, en la imagen inferior izquierda de la lámina 39 del Códice Fejérváry-Mayer (C. A. Burland, ed., Códice Fejérváry-Mayer [Graz, Austria: Akademische Druck- und Verlagsanstalt, I97I]), 39 . 
esquemática del extremo de las plumas secundarias del águila, anchas y redondeadas, usual en ornamentos y piezas ceremoniales indígenas (fig. $2 \mathrm{c}$ ). ${ }^{8} \mathrm{Y}$ la orla propiamente dicha está formada por un diseño convencional que conocemos como plumón de sacrificio, una abstracción pictográfica ${ }^{9}$ que representa cada uno de los puñados de pequeñas plumas de garza que se pegaban en el cuerpo de las víctimas sacrificiales, así como en las banderas y escudos usados en el ritual (fig. 2d). La combinación del despliegue de las plumas de punta redondeada y los plumones de sacrificio ocurre en la escultura mexica de la cabeza de Coyolxauhqui; en ese caso, además, la sucesión de tres redondeles de plumas y el diseño de un círculo en el centro da lugar a la forma de una flor (fig. 3). ${ }^{\text {Io }}$

No sólo la orla de plumones hace referencia al sacrificio, la flor misma, que aparece abierta en el centro del disco, es uno de los símbolos más expresivos del sacrificio humano ritual entre los nahuas. ${ }^{\text {II }}$ En algunos cantos religiosos indígenas, aún en uso en el siglo XVI, ${ }^{12}$ se habla de la herida sacrificial con la metáfora de una flor que abre. En las mismas líneas se describe el lugar de la batalla y la circunstancia del sacrificio con alusiones al águila, a las plumas preciosas, a las plumas que bullen o se agitan en el campo y al escudo o chima$l i .^{13} \mathrm{El}$ disco de cerámica incluye las plumas de los tocados guerreros, el plumón

8. Por ejemplo en el cuauhxicalli o recipiente sacrificial mexica del Museum für Völkerkunde de Viena. Nelly Gutiérrez Solana Rickards, Objetos ceremoniales en piedra de la cultura mexica (Ciudad de México: Universidad Nacional Autónoma de México, I983), 85 y láms. 50 y 51.

9. Aparece con frecuencia en los escudos de guerra y también en el arreglo corporal de víctimas sacrificiales, por ejemplo en el Códice Telleriano Remensis. Véase Eloise Quiñones Keber, Codex Telleriano Remensis. Ritual, Divination, and History in a Pictorial Aztec Manuscript (Austin: University of Texas Press), recurrente entre el folio $27 \mathrm{r}$ y el $42 \mathrm{v}$.

Io. Esther Pasztory, Aztec Art (Nueva York: Harry Abrams Publishers, I983), I52-I54.

II. Christian Duverger, La flor letal. Economía del sacrificio azteca, trad. J. J. Utrilla (México: Fondo de Cultura Económica, 1983), 204-206.

I2. En el manuscrito Cantares mexicanos se recoge la lírica ceremonial de tradición prehispánica que los indígenas seguían interpretando en las fiestas cristianas. Fue compilado a instancias de fray Bernardino de Sahagún y consiste en la transcripción de cantos ofrecidos por los propios intérpretes indígenas entre las décadas de 1550 y 1570 . El manuscrito se conserva en la Biblioteca Nacional de México, en la unam. Cantares mexicanos. Songs of the Aztecs, ed. John Bierhorst (Stanford, California: Stanford University Press, 1985).

13. Por ejemplo en el folio 6 del manuscrito. Traducciones: Cantares mexicanos, I48-I50; Pablo Escalante Gonzalbo y Erik Velásquez García, “Orígenes de la literatura mexicana. Oralidad, pictografía y escritura de los pueblos indígenas”, en Erik Velásquez García, Antonio Rubial, Manuel Sol y Alejandro Toledo, coord. Enrique Florescano, Literatura, Historia Ilustrada de México (México: Debate/Consejo Nacional para la Cultura y las Artes, 20I4), 25-29. 


\begin{tabular}{|c|c|c|c|}
\hline Figura & Posición en el disco & Forma & Ejemplo en Mesoamérica \\
\hline $\begin{array}{l}\text { FIGURA 2A } \\
\text { Líquido en } \\
\text { movimiento }\end{array}$ & & & $\begin{array}{c}\text { Representación del líquido } \\
\text { en movimiento en la lámina } 20 \\
\text { del Códice Borgia }\end{array}$ \\
\hline $\begin{array}{l}\text { FIGURA 2B } \\
\text { Torzal }\end{array}$ & & & $\begin{array}{l}\text { O } 000000 \\
\text { Torzal en la imagen inferior } \\
\text { izquierda de la lámina } 39 \\
\text { del Códice Fejérváry-Msyer }\end{array}$ \\
\hline $\begin{array}{l}\text { FIGURA 2C } \\
\text { Plumas } \\
\text { secundarias } \\
\text { del águila }\end{array}$ & & & 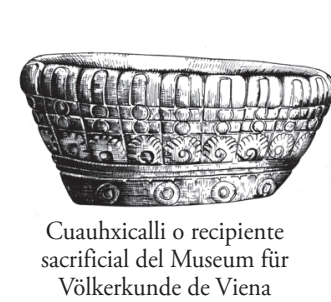 \\
\hline $\begin{array}{l}\text { FIGURA 2D } \\
\text { Plumón } \\
\text { de sacrificio }\end{array}$ & है & & $\begin{array}{c}\text { Víctima de sacrificio } \\
\text { en el folio } 40 \mathrm{v} \text {. } \\
\text { del Códice Telleriano Remensis }\end{array}$ \\
\hline
\end{tabular}

2. Tabla comparativa. Dibujos: Aban Flores Morán. 
DOI: http://dx.doi.org/10.22201/iie.18703062e.2018.113.2659

88

PABLO ESCALANTE GONZALBO
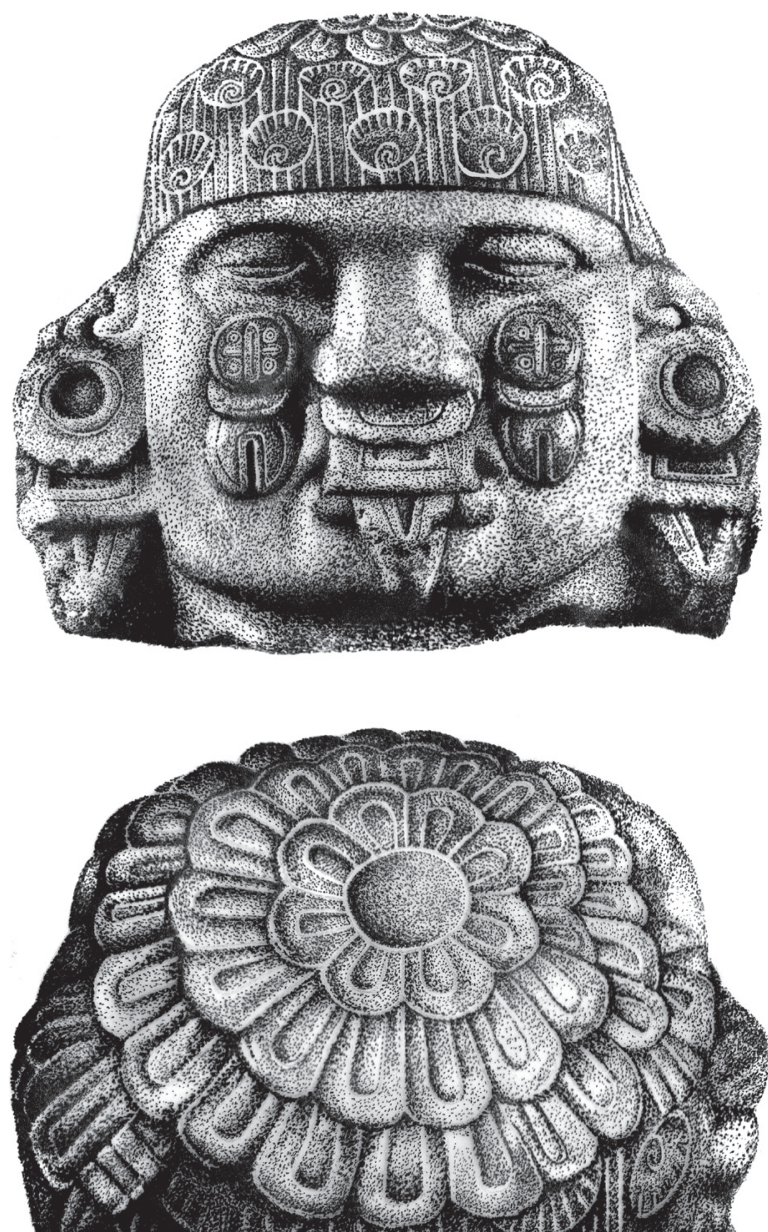

3. Vistas frontal y superior de una escultura mexica de la cabeza de Coyolxauhqui. Museo Nacional de Antropología. Dibujo: Aban Flores Morán. 
diminuto y volátil de la garza y la flor abierta, pero reproduce también la forma de un escudo indígena. Es verdad que el disco mide la mitad del diámetro de un chimalli, pero significativamente la flor que lleva en su centro es un girasol, lo que los nahuas llamaban chimalxóchitl, flor-escudo.

A todos estos elementos indígenas, sobre los que volveremos después, explicables en clave de la tradición religiosa mesoamericana, se les superpone una cruz latina, una cruz cristiana colocada sobre una base con forma de trapecio, que recuerda la forma de algunos altares del Posclásico (fig. 4a). ${ }^{\mathrm{I}} \mathrm{Y}$ por cierto, los artesanos que realizaron el disco fabricaron también al menos cuatro placas de cerámica de grandes dimensiones con forma de trapecio, que debieron estar pensadas para cubrir la mampostería de sendos altares (fig. 4b). La plataforma de la cruz está integrada por lo que parecen eslabonamientos verticales de plumaria. En la base, en el filo de ese diseño, se advierten los pelillos desordenados de la naciente de una pluma, una curiosidad de diseño que aparece en plumas de algunos vasos sacrificiales mexicas, ${ }^{15}$ en diversos códices, ${ }^{16}$ y que se reprodujo en otras piezas de cerámica relacionadas con este disco. Una interpretación alternativa para la base de la cruz sería que las cuatro tiras representaran chorros de sangre, diseño muy común en los códices, que suele marcar altares y escalinatas de templos. ${ }^{17}$

Semejante asociación de la cruz cristiana con símbolos sacrificiales indígenas no es exclusiva de esta pieza. Ocurre, por ejemplo, en la cruz atrial de la iglesia dominica de Topiltepec, en la Mixteca, ${ }^{18}$ y en el monolito del águila y el

I4. En el pie de foto de una reproducción del disco de cerámica se describe así “Christian cross in the center on top of a momoztli". En efecto el trapecio empinado parece representar un altar o momoztli. Enrique Rodríguez-Alegría, "The Aztecs After the Conquest", en The Aztec World, ed. Elizabeth Brumfiel y Gary Feinman (Nueva York: Harry Abrams, 2008), 20I. La forma también se asemeja a algunas piedras sacrificiales del Posclásico.

I5. Por ejemplo en el interior del gran cuauhxicalli del felino del Museo Nacional de Antropología.

16. No se omite el detalle de las pequeñas pilosidades en la base de las plumas en el tratado de arte plumaria del Códice florentino. Véase el Códice florentino, ed. facsimilar (México: Archivo General de la Nación, 1979), vol. 2, lib. IX, f. 63r. a 67r.

17. Por ejemplo, en la escalinata del templo del Cerro del Mono, Códice Nuttall, lám. 5.

I8. Alfonso Caso, "La Cruz de Topiltepec", en Estudios antropológicos en homenaje al doctor Manuel Gamio, eds. Wigberto Jiménez Moreno y Alfonso Ortega Martínez (Ciudad de México: Universidad Nacional Autónoma de México, Sociedad Mexicana de Antropología, 1956, I77-I78). Pablo Escalante Gonzalbo, "Cristo, su sangre y los indios. Exploraciones iconográficas sobre el arte mexicano del siglo XvI", en Herencias indígenas, tradiciones europeas y la mirada europea, ed. Helga von Kügelgen (Fráncfort del Meno: Vervuert, 2002), 76-79. 

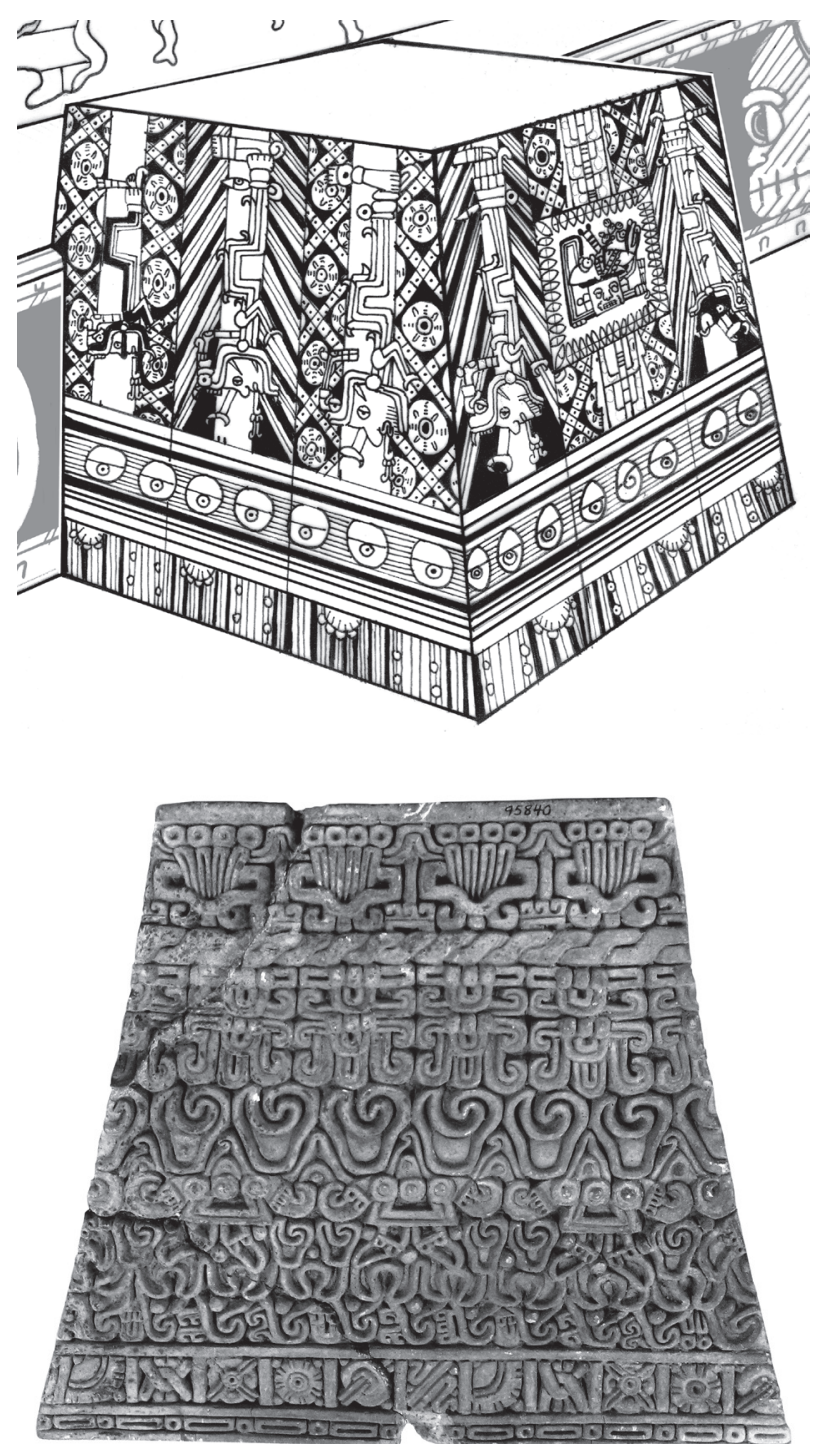

4a. Altar prehispánico de forma trapezoidal con pintura mural. Ocotelulco, Tlaxcala. Dibujo: Aban Flores Morán; b) Placa de cerámica en forma de trapecio destinada a cubrir el frente de un altar de mampostería similar a los prehispánicos. En la cenefa de la parte inferior puede observarse, de izquierda a derecha, un motivo no identificado, la fecha calendárica Nahui Ollin, una flor de cuatro pétalos, un círculo de papel plisado, un chalchihuite o cuenta de jade con pendiente y el símbolo ílhuitl (día, fiesta). Foto: Pablo Escalante. 
jaguar en la plaza de Huaquechula, Puebla, piedra sacrificial prehispánica que ostenta un chimalli con plumones de sacrificio en cuyo campo se inscribió una cruz. También es oportuno mencionar los estandartes y pendientes de plumaria y oro elaborados en Tepetlaoztoc, zona de Tetzcoco, para entregar como tributo al encomendero Gonzalo de Salazar. ${ }^{19}$ En dos de ellos se representa la cruz cristiana en objetos cuya técnica, estilo y ornamentación son plenamente indígenas. Tal es el caso del estandarte en el cual un mono enrosca su cola en el travesaño de la cruz (fig. 5). ${ }^{20}$

\section{La colección}

Es indispensable ahora referirnos a la procedencia del disco de cerámica. Como decíamos, el disco pertenece a una de las colecciones llevadas por Starr al Field Museum. Frederick Starr (I858-1933), profesor de antropología de la Universidad de Chicago, reunió durante varios años materiales arqueológicos mexicanos; tuvo noticia de algunas colecciones ya existentes y gestionó su traslado a los Estados Unidos. Lo hizo como una empresa personal, pero todo indica que el objetivo, a fin de cuentas, era ofrecer estas colecciones al museo de la ciudad en cuya universidad trabajaba. ${ }^{2 \mathrm{I}}$ Concretó la adquisición de la Colección Abadiano, con piezas de la costa del Pacífico mexicano, en $1894,{ }^{22}$ y entre ese año y I897 formó por su cuenta una colección de cerámica matlatzinca, la Colección Tlacotepec, con la ayuda de un misionero bautista de nombre W. D. Powell, residente en Toluca. El misionero y el antropólogo montaron un plan en el que la tarea del primero era "dirigir" las excavaciones realizadas por los propios habitantes de las faldas del cerro de Tlacotepec y la de Starr buscarle un destino

19. Perla Valle, Códice de Tepetlaóztoc (Códice Kingsborough) (Toluca: El Colegio Mexiquense, 1994), 63-9I.

20. Códice de Tepetlaóztoc (Códice Kingsborough), ed. facsimilar de Perla Valle (Toluca: El Colegio Mexiquense, 1994), fol. I9 B.

2I. Donald McVicker, "Prejudice and Context: The Anthropological Archaeologist as Historian”, en Tracing Archaeology's Past: The Historiography of Archaeology, ed. Andrew L. Christenson (Carbondale, Illinois: Southern Illinois University Press, I989), II3-I26, I2I.

22. Donald McVicker, "Las colecciones de arqueología de México del Field Museum", en Mexico: la visión del cosmos. Three Thousand Years of Creativity (Chicago: The Mexican Fine Arts Center Museum, I992), 68. 


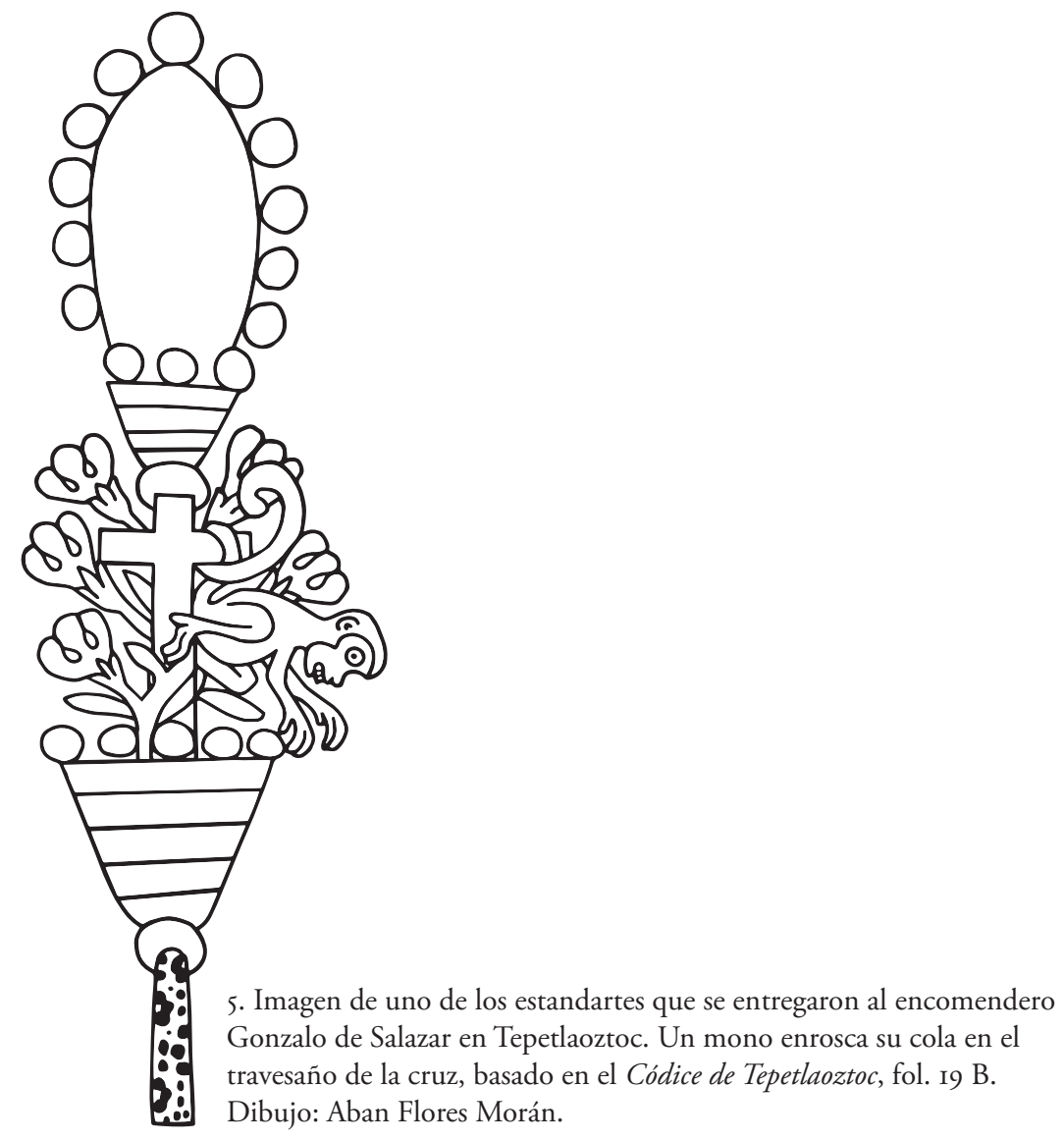

a las piezas del otro lado de la frontera. Al parecer, el propio Starr compró la mayor parte de las piezas de Powell. ${ }^{23}$

Powell le había hablado a su socio de otra colección en la que había materiales teotihuacanos, la de Antonio Peñafiel. Al comprender que era viable y redituable vender estos materiales en los Estados Unidos, el pastor emprendió por su propia cuenta la compra de la colección y la envió a través de la frontera. Pensaba venderla por \$3,000 dólares. Sin embargo, se vio en un apuro económico y optó por ofrecérsela a Starr por sólo \$1,700 dólares. Esto ocurrió en el mismo año de I897. ${ }^{24}$

23. McVicker, "Las colecciones", 70.

24. McVicker, "Las colecciones", 70. 
En 1904 Starr dio un giro a sus intereses académicos y decidió ocuparse del estudio de los pigmeos. No tenía dinero para emprender su proyecto africano y optó por vender al Field Museum todo lo que había reunido hasta entonces. El Is de septiembre de 1905 el Museo le pagó \$9,000 dólares y así adquirió toda la colección de Tlacotepec, cientos de objetos arqueológicos diversos y la Colección Peñafiel, ${ }^{25}$ que estaba formada por I,475 objetos. ${ }^{26}$ Se trata de piezas arqueológicas principalmente de barro, procedentes de diferentes sitios de Mesoamérica, entre ellas las de Teotihuacán, compradas a Powell.

Antonio Peñafiel (I830-I922) había formado su colección al mismo tiempo que se dedicaba al estudio de los vestigios y documentos del pasado indígena y a la edición de fuentes. ${ }^{27}$ En particular, se interesó por la ciudad de Teotihuacán, entabló contacto con los lugareńos y se hizo de diversos objetos. Nunca estuvo en condiciones ni tenía el conocimiento o el propósito de hacer una excavación formal, pero sí descubrió dos sitios de interés: una habitación con pintura mural del periodo Clásico, situada en el barrio de San Sebastián, en un lugar llamado Teopancaxco, ${ }^{28}$ y un conjunto de restos cerámicos procedentes en su totalidad de un mismo sitio, en el barrio de la Purificación, en el que había unas chozas pertenecientes a un campesino de nombre Pilar Vargas. ${ }^{29}$ Vale la pena citar literalmente a Peñafiel: "Milagrosamente se salvaron estas reliquias, sepultadas en los escombros de la casa misma del alfarero, y descubiertas después por el arado de la milpa."30

En el capítulo XIII de su libro sobre Teotihuacán, Peñafiel habló de ambos hallazgos y en la sección de láminas publicó fotografías de varias de las piezas. Lo que más le había llamado la atención eran los moldes, pero no publicó fotos de ellos, sino de los vaciados que mandó hacer ex profeso. También incluyó imágenes de algunas de las piezas que se encontraron en positivo. Todas ellas coinciden con materiales que están en un mismo grupo de anaqueles y cajones de la colección Peñafiel/Starr en el Field Museum, con una numeración suce-

25. McVicker, "Las colecciones", 70.

26. Carta de Frederick Starr al Dr. George A. Dorsey, I de agosto de I905, Chicago, 4. Archivos del Field Museum. Expediente 947.

27. Obras del doctor Antonio Peñafiel y su biografía (no se acredita autor) (Ciudad de México: Sociedad Impresora, 1904); Jesús Galindo y Villa, El Dr. Antonio Peñafiel: un aspecto de su vida, t. 45 (Ciudad de México: Boletín de la Sociedad Mexicana de Geografía y Estadística, 1930).

28. Peñafiel, Teotihuacán, 49.

29. Peñafiel, Teotihuacán, 50.

30. Peñafiel, Teotihuacán, 50. 
siva. Es decir, la colección que Peñafiel llamó de "la casa del alfarero" está en dicho museo, y abarca las piezas 95.735 a 95.85I y I64.84I a I64.866.

A Peñafiel le llamó la atención el disco con la cruz, así que fue una de las piezas que escogió fotografiar. Se refirió a ella en unas líneas del texto, señaló que la decoración que acompañaba a la cruz era de "estilo antiguo" y, para explicar la presencia de este disco de la cruz al lado de moldes y piezas con motivos que él juzgaba prehispánicos, escribió: "Esta unión de lo antiguo clásico y de lo colonial, se explica fácilmente, si los descendientes del alfarero antiguo alcanzaron la época de los conquistadores." ${ }^{11}$

Peñafiel reconoció la unidad de esos materiales y tuvo el acierto de identificar la colección como perteneciente a un taller: en efecto, es la única manera de explicar la presencia de abundantes moldes y de piezas relacionadas con ellos. También estaba consciente del tipo de suceso que justificaba el hallazgo de materiales bien conservados, agrupados, vinculados entre sí. Es posible que él mismo haya atestiguado la extracción, también pudo narrárselo Pilar Vargas: se trataba de un desplome, la habitación había colapsado, con todos aquellos materiales en su interior.

Ahora bien, Peñafiel no hizo una distinción entre el material de ese hallazgo y otros objetos de la antigua ciudad. Para él todo (salvo el disco con la cruz) era antiguo, incluso lo llama "clásico". Hasta ahora, la propia museografía del Field Museum, que incluye cuatro o cinco figuras de "la casa del alfarero" dentro de una vitrina con objetos del Teotihuacán clásico, también asumía la pertenencia de esas piezas a la cultura teotihuacana. No hay, sin embargo, un solo rasgo en los vestigios del taller de alfarería que sea propiamente de estilo teotihuacano. Sí hay motivos del Posclásico, interpretados con cierta libertad y combinados con otras formas desconocidas en el repertorio prehispánico.

Efectivamente, el disco con la cruz latina es la pieza que muestra de manera más ostensible un elemento ajeno al repertorio prehispánico. ¿Qué sucede con las demás piezas?

El conjunto de piezas de barro de "la casa del alfarero" suma unos I4I ejemplares de diversos tamaños. La mayor parte son pequeños, caben en la mano, pero también hay algunas piezas decorativas mayores, como el propio disco de la cruz. Hay tanto moldes como piezas acabadas. Los temas y el estilo de piezas y moldes son afines. He detectado hasta ahora un caso en el que un molde 


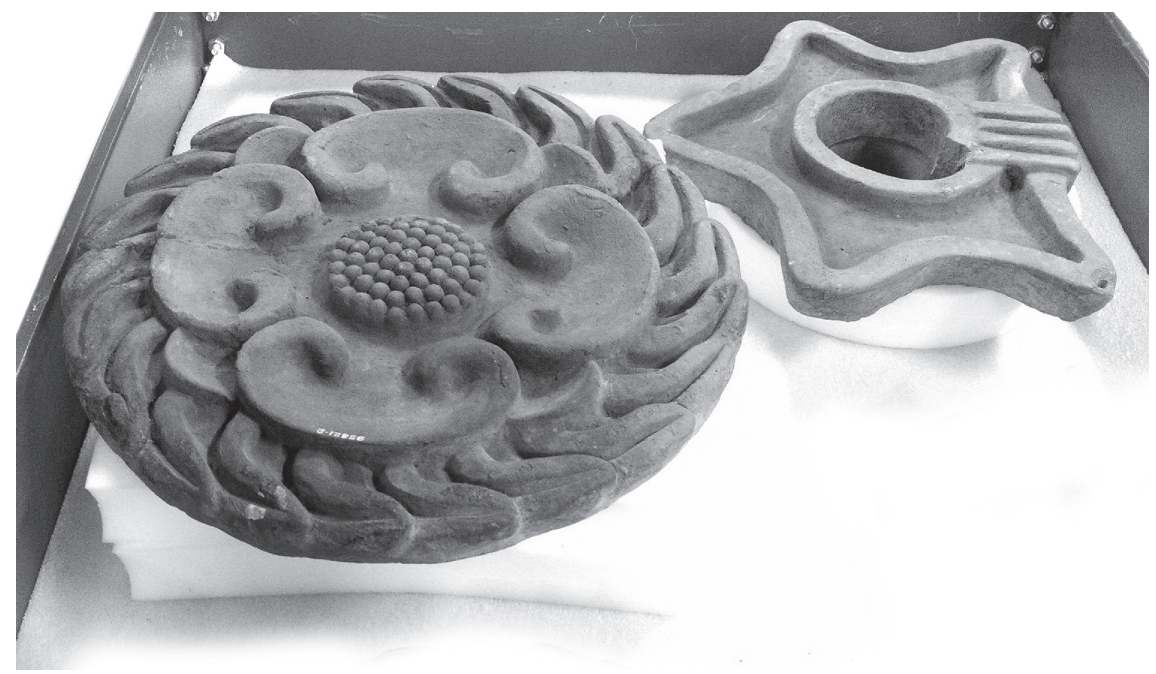

6. Ornamentos circulares para anclar en frisos arquitectónicos; a) disco de plumas con flor, diámetro, 3I cm; b) caracol segmentado con cinta, diámetro aprox. $28 \mathrm{~cm}$. Cortesía The Field Museum, núms. cat. 95821, 95823. Foto: Pablo Escalante Gonzalbo.

coincide estrictamente con un positivo, es decir, que se trata de una pieza salida de ese mismo molde. ${ }^{32}$

La gran mayoría de las piezas son planas y carecen de vista tanto en sus cantos como en su reverso. Esto indica que se trata de piezas hechas para ser miradas sólo de frente. Y puesto que no tienen punto de apoyo alguno, lo más probable es que hayan sido concebidas para fijarse con mezcla en un muro. Al menos tres de ellas (fig. 6) ${ }^{33}$ tienen una suerte de anillo prominente en el reverso; parece tratarse de decoración para frisos, a la manera de los clavos escultóricos de círculos o flores que solían decorar los palacios y los templos en la época prehispánica y también en el siglo Xvi. ${ }^{34} \mathrm{El}$ resto de las piezas no muestra este tipo de recurso para la incrustación, por lo que parece haber sido pensado para pegarse más que para empotrarse.

32. Se trata de la pieza con número de catálogo 95.798 y del molde I64.842.

33. Números 95820, 95821 y 95823.

34. James B. Kiracofe, "Architectural Fusion and Indigenous Ideology in Early Colonial Teposcolula. The Casa de la Cacica: A Building at the Edge of Oblivion”, Anales del Instituto de Investigaciones Estéticas, núm. 66 (I995): 45-84. 
La visión del conjunto sugiere que se trata de un mosaico cerámico en proceso; todos los materiales estaban en el mismo taller en el que se realizaba la producción, de allí que hubiera los mismo moldes que piezas acabadas.

\section{Las piezas del taller}

Las piezas de apariencia más precolombina, por así decirlo, en el conjunto son dos tableros con forma de trapecio (fig. 4b), así como fragmentos de otros dos. ${ }^{35} \mathrm{Y}$, sin embargo, la definición de las formas y la combinación elegida no se corresponden con ningún ejemplo prehispánico que conozcamos. Puede apreciarse la forma repetida del pictograma tépetl o montaña, tal como se representaba en vísperas de la Conquista. También hay algunas plumas, lazos y cuentas, todo ello con rasgos no idénticos a los de la iconografía conocida del Posclásico. En la cenefa de la base de uno de los tableros (fig. 4b) (si asumimos que la base es el lado más ancho del trapecio, como en los altares indígenas) se aprecia (tras un primer motivo no identificado) la fecha calendárica 4 Movimiento (Nahui Ollin en náhuatl), nombre de la quinta edad o Sol, la era de los hombres. En la misma cenefa pueden verse una flor de cuatro pétalos; un disco que corresponde con las representaciones pictográficas del círculo de papel plisado de algunos sacrificios; lo que parece un chalchihuite o cuenta de jade representado como orejera (con un pendiente en el centro), y el símbolo que llamamos ilhuitl, que alude a la noción de día sagrado o fiesta y que vemos también en la pintura mural del convento de Malinalco, en la bóveda. ${ }^{36}$

La presencia de símbolos reconocibles en el repertorio prehispánico, pero en una composición que no identificamos en obras y fuentes antiguas, ocurre en algunas obras del siglo xvi, como el convento de Malinalco, antes citado. Que estos trapecios no son vestigios de una etapa anterior del taller cerámico sino obras contemporáneas a las demás, puede deducirse de la afinidad en el material y la técnica con el resto del conjunto. Además, varias de las formas representadas en los trapecios existen sueltas, como moldes o como formas en positivo, en el mismo grupo: es el caso del monte, algunas figuras de las plumas,

35. Trapecio A, con cenefa de Nahui Ollin (95840); trapecio B, con largas plumas (95839); además de 95795 y $9584 \mathrm{I}$.

36. Jeanette Favrot Peterson, The Paradise Garden Murals of Malinalco (Austin: University of Texas Press, 1993), 47-49. 
así como las cuentas del borde inferior. La forma de trapecio de ambas placas resulta tan curiosa para la tradición occidental como es familiar a la cultura ceremonial del Posclásico mesoamericano: se trata de la forma que típicamente adoptaban los altares, sobre los cuales se colocaban las ofrendas. Hay representaciones pictóricas como, por ejemplo, en el tonalámatl del Borgia, ${ }^{37}$ y algunas obras de mampostería aún conservadas, como la del templo de Ocotelulco, Tlaxcala (fig. 4a).

También hay, entre las piezas y moldes de la colección, algunas formas mucho más naturalistas, afines a las que se aprecian en grabados del siglo XVI, y a las que se usaron en viñetas de obras como la de fray Diego Durán (I537I588) ${ }^{38}$ o fray Bernardino de Sahagún (I499-1590) ${ }^{39}$ y también en la decoración conventual. Tal es el caso de una cenefa curva con una sucesión de flores ligadas a un tallo ondulante (fig. $7 \mathrm{a}$ ); ${ }^{\circ}$ el molde para una cenefa recta con otro tipo de flores, como capullos de madreselvas o freesias (fig. $7 \mathrm{~b}$ ); ${ }^{4 \mathrm{I}} \mathrm{el}$ molde para una hoja de lirio (fig. 7c); ${ }^{42} \mathrm{o}$ bien moldes con la figura de un pájaro (fig. $7 \mathrm{~d}$ ). ${ }^{43}$

La sensación de disparidad de la colección empieza a disiparse cuando se descubre la repetición de figuras y la conexión existente entre distintas piezas y moldes, con diversas combinaciones que comparten motivos entre sí. Esto confirma la idea de la contemporaneidad del conjunto y, más aún, la de su probable pertenencia a un mismo programa decorativo que incluiría algunos símbolos de origen antiguo, desprovistos de cualquier alusión que se pudiera considerar directamente idolátrica, y otros temas nuevos. Las placas con forma de trapecio, por ejemplo, exhiben motivos, como flores y plumas, que aparecen en varios moldes sueltos de la colección. Como en este momento aún trabajo en el análisis comparativo de todo el conjunto, me quiero limitar a la presentación de cuatro piezas (fig. 8): el disco del que ya he hablado y otros tres, relacionados con éste. En realidad, dos de ellos son piezas acabadas para cuya elaboración se utilizó un molde y las otras dos son moldes para realizar sendos

37. Códice Borgia, lám. 63.

38. Fray Diego Durán, Historia de las Indias de la Nueva España e Islas de Tierra Firme, ed. Ángel María Garibay K., 2 vols. (México: Editorial Porrúa, 1967).

39. Fray Bernardino de Sahagún, Códice florentino (Historia general de las cosas de la Nueva Espańa), ed. facsimilar, 3 vols. (México: Secretaría de Gobernación, 1979).

40. Número 95846.

4I. Número 95736.

42. Número 95785 .

43. Por ejemplo, número 95806. 

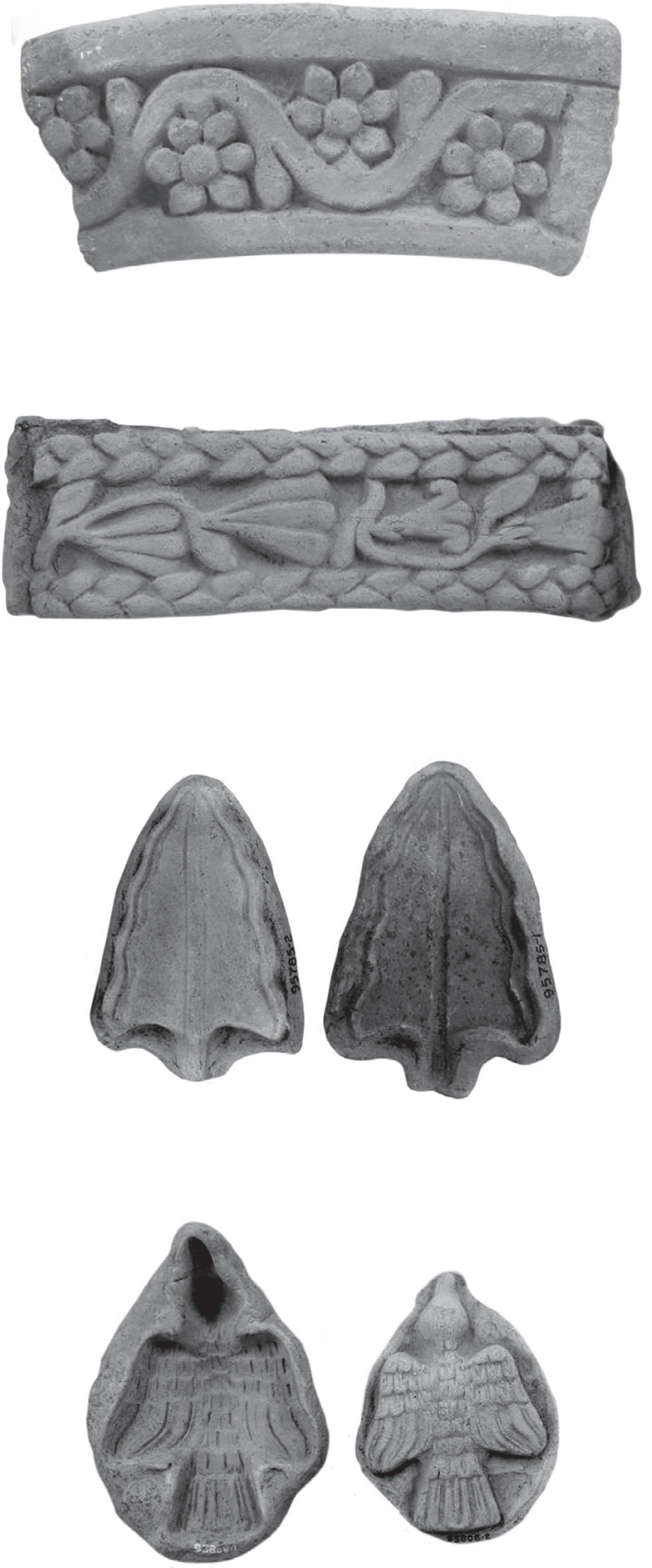

7a) Cenefa curva con una sucesión de flores ligadas a un tallo ondulante, $3.8 \times 10 \mathrm{~cm}$. Cortesía The Field Museum, núm. cat. 95846; b) prueba realizada por Peñafiel, a partir del molde original para una cenefa recta con flores y capullos de madreselvas o freesias, $8.5 \times 21 \mathrm{~cm}$. Cortesía The Field Museum, núm. cat. 95736; c) molde para una hoja de lirio (derecha) y la prueba de vaciado elaborada por Antonio de Peñafiel (izquierda), $8.2 \times 5.8 \mathrm{~cm}$. Cortesía The Field Museum, núm. cat. 95785 ; d) molde con la figura de un pájaro (izquierda) y positivo de prueba elaborado por Antonio de Peñafiel, $12 \times 8.5 \mathrm{~cm}$. Cortesía The Field Museum núm. cat. 95806. Fotos: Pablo Escalante Gonzalbo. 

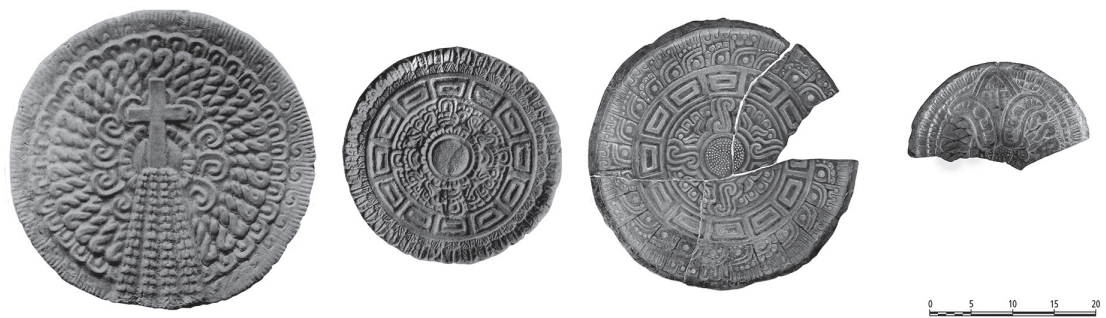

8. Los cuatro discos de cerámica de la Colección Peñafiel: a) disco de la cruz latina, $36 \mathrm{~cm}$, $4.63 \mathrm{~kg}$; b) disco de los cuatro remates de plumas, $25.5 \mathrm{~cm}, \mathrm{I} .6 \mathrm{~kg}$; c) molde de las cuatro volutas, $32.5 \mathrm{~cm}, 2.17 \mathrm{~kg}$; d) molde de la mazorca de maíz, I8 cm, $.398 \mathrm{~kg}$. Para los dos moldes he utilizado un procedimiento de inversión de la imagen de Photoshop. Cortesía The Field Museum, núms. cat. 95851, 95816, 95838, I64854. Fotos: Pablo Escalante Gonzalbo.

discos. Las llamaré disco de la cruz latina (fig. I), 44 disco de los cuatro remates de plumas (fig. 9a), ${ }^{45}$ molde de las cuatro volutas (fig. I0) ${ }^{46}$ y molde de la mazorca de maiz (fig. II). ${ }^{47}$

\section{Los discos}

Las cuatro piezas circulares son básicamente similares por su material, su técnica, la apariencia general de su estilo e incluso sus dimensiones, si bien el molde de la mazorca es más pequeño. Los cuatro están decorados con algunos elementos que tienen su origen en el repertorio prehispánico, pero en ninguno de los cuatro es reconocible una iconografía prehispánica propiamente dicha: no hay una composición que encontremos tal cual en el repertorio antiguo..$^{4}$ Se trata de obras (dos de ellas, ya decíamos, sólo apreciables por los moldes que iban a emplearse para ejecutarlas) cuya única función parece haber sido decorar una superficie arquitectónica: no se paran, no sirven para sujetar o contener nada, deben ser colocadas en una superficie vertical para verse.

44. Número de inventario 95851, diámetro $36 \mathrm{~cm}$.

45. Número $958 \mathrm{r} 6$, diámetro $25.5 \mathrm{~cm}$.

46. Número 95838, diámetro $32.5 \mathrm{~cm}$.

47. Número 164854 , diámetro aproximado (la pieza está rota y falta una parte) $18 \mathrm{~cm}$.

48. El caso más cercano sería el de la cabeza de Coyolxauhqui que mencioné antes. 

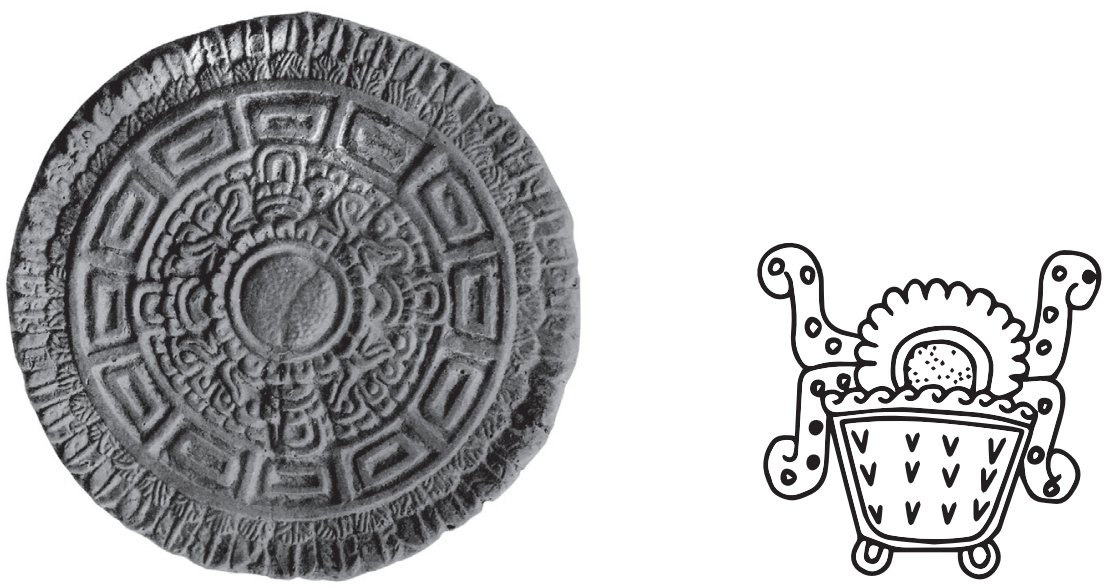

9a) Disco de los cuatro remates de plumas, $25.5 \mathrm{~cm}$. Presenta un girasol en el centro del cual surgen cuatro vírgulas que se bifurcan y cuatro remates de ornamentos plumarios que forman una cruz. En la siguiente circunferencia se encuentran doce rombos, seguidos por nacientes de plumas y plumas secundarias de águila. Cortesía de The Field Museum, núm. cat. 95816. Foto: Pablo Escalante Gonzalbo; b) brasero con una bola de zacate impregnada de copal y sangre, en combustión a ambos lados, dos vírgulas de humo se bifurcan. Códice Borgia, lám. 63. Dibujo: Aban Flores Morán.

En cuanto a su iconografía, las cuatro comparten un mismo elemento central que es una flor. Esta flor se caracteriza por tener un enorme centro que se conoce en botánica como "capítulo" y tiene, en la naturaleza, una infinidad de inflorescencias usualmente de intenso color amarillo. Los grandes capítulos centrales se presentan en las asteráceas como la margarita, y son particularmente grandes, con mayor superficie que la corola, en el girasol. Tanto el disco de la cruz latina, como el disco de los cuatro remates de plumas y el molde de la mazorca de maíz muestran el gigantesco capítulo rodeado de pétalos muy pequeńos característico del girasol. En el molde de las cuatro volutas no se advierte la corola, pero el capítulo es igualmente grande. En cuanto a las inflorescencias, son muy ostensibles en tres discos y no lo son en el de la cruz latina. En el molde de las cuatro volutas se advierte bien la técnica de elaboración de esta forma, con múltiples incisiones que en el positivo aparecen como pequeńas bolitas.

Tal es el centro de las cuatro piezas, un girasol. Alrededor de la flor apreciamos esa sucesión de crestas, como de líquido que fluye, tanto en el disco de la cruz 


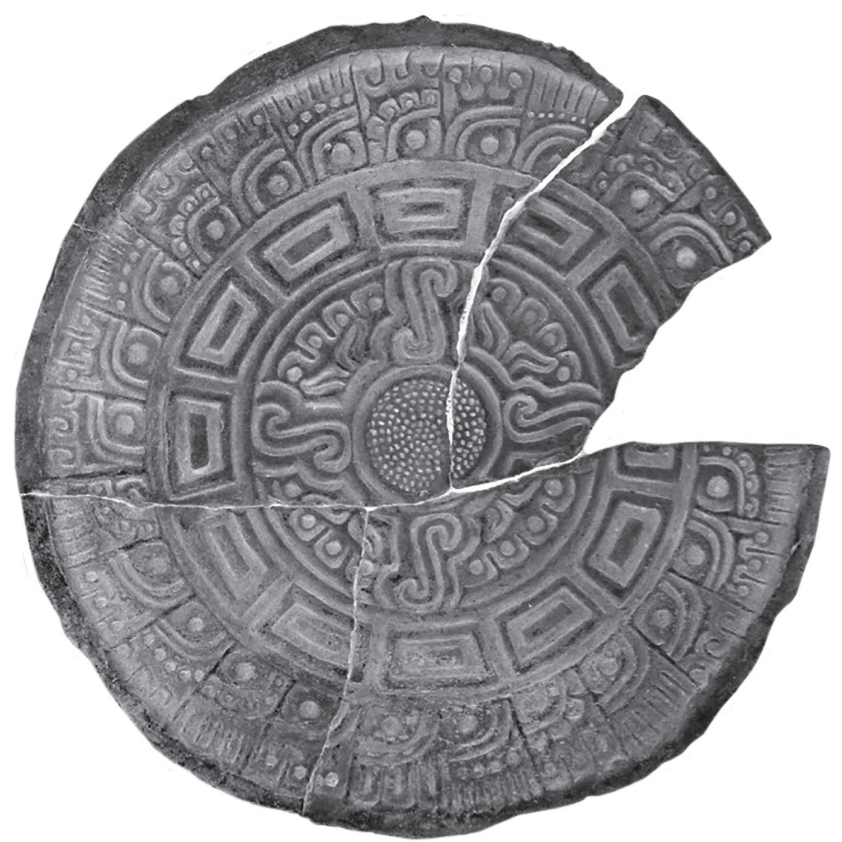

Io. Imagen invertida digitalmente del molde de las cuatro volutas, $32.5 \mathrm{~cm}$. En el centro se advierte el capítulo del girasol, del cual surgen cuatro vírgulas de humo que se bifurcan. Alternando con las vírgulas, cuatro grandes volutas forman una cruz, y entre ellas cuatro largas volutas que forman una cruz. A continuación se despliega la cenefa circular de los doce rombos y finalmente un motivo con variaciones semejante a un ojo emplumado. Cortesía The Field Museum, núm. cat. 95838. Foto: Pablo Escalante Gonzalbo.

latina como en el molde de la mazorca de maíz. También es común a ambas piezas el despliegue radial de torzales. Y ambas tienen diseńos plumarios en su circunferencia exterior, salvo que el molde de la mazorca no muestra el pictograma de plumón de sacrificio.

Por su parte, el disco de los cuatro remates de plumas y el molde de las cuatro volutas, que no tienen las ondulaciones de presunto líquido ni el torzal, comparten dos rasgos muy notables. Uno de ellos son los cuatro brotes de vírgulas que se bifurcan, reminiscentes aunque no idénticas a las representaciones pictográficas prehispánicas del humo que surge de las ofrendas en proceso 


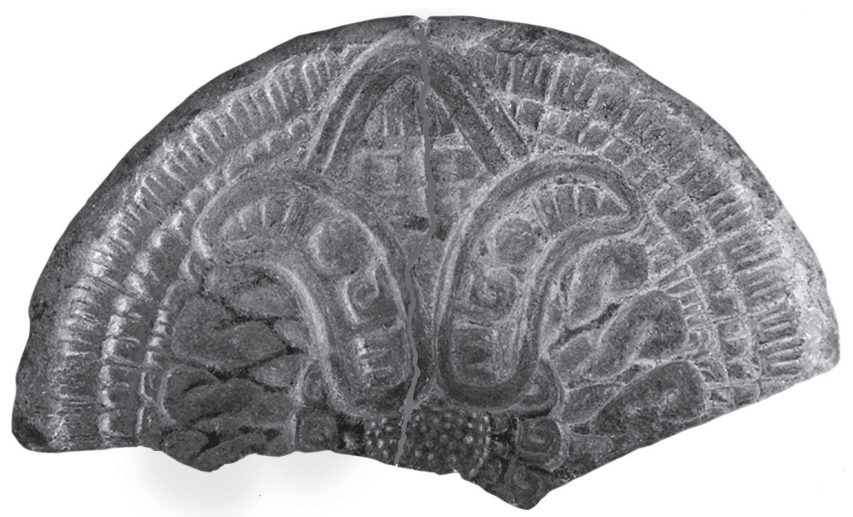

II. Imagen invertida digitalmente del molde de la mazorca de maíz $(\mathrm{I} 8 \mathrm{~cm})$. En su centro se advierte una flor de girasol, seguida por una sucesión de crestas (que he identificado como representación del líquido que fluye), torzales y tres circunferencias de plumas. De todo el conjunto emerge, y ocupa el primer plano, una mazorca de maíz con dos hojas abiertas a sus lados. Cortesía The Field Museum, núm. cat. I64854. Foto: Pablo Escalante Gonzalbo.

de quemarse (fig. 9b). ${ }^{49} \mathrm{Y}$ el otro rasgo en común entre los dos es una cenefa circular con una sucesión de doce trapecios.

La presencia de las plumas es más clara en la orla del disco de los cuatro remates de plumas. En el disco de la cruz latina, como hemos visto, la orla está formada por representaciones estereotipadas del plumón de garza y en la circunferencia previa a la orla hay también una sucesión de plumas. En el molde de la mazorca de maíz parece haber tres circunferencias plumarias sucesivas. Y finalmente la orla del molde de las cuatro volutas presenta un motivo variable y complejo, que recuerda al glifo ojo de reptil, y que por el momento no puedo resolver.

49. Surgen de una ofrenda que arde en una imagen del tonalámatl del Códice Borgia, lám. 63. Se advierten surgiendo de las bolas de zacate (zacatapayolli) en las cajas mexicas de ofrendas, labradas en piedra. Por ejemplo, cajas 2 y 3 en Gutiérrez Solana Rickards, Objetos ceremoniales, figs. 13, 17, 2I. 
La cruz, el sacrificio y el cuerpo de Cristo

A simple vista, hay una diferencia fundamental entre el disco de la cruz latina y los otros tres y es, justamente, ésa: que ostenta la cruz. Así lo vio Peñafiel cuando destacó la presencia de esta pieza dentro del conjunto. A su juicio, y para cualquiera en un primer acercamiento, parecería que es la única pieza propiamente cristiana. Sin embargo, los cuatro discos son muy semejantes y parecen haber estado destinados a un mismo uso; comparten, como hemos visto, diferentes elementos en combinaciones distintas, y todo indica que son contemporáneos. Esto nos pide valorar también las posibles semejanzas en su significado.

Los cuatro discos tienen la flor abierta en su centro, motivo ligado fuertemente a la idea de la herida sacrificial en la tradición mesoamericana y en la nahua en particular. Se trata de un girasol, chimalxóchitl, que semánticamente relaciona la decoración con el concepto de escudo de guerra o chimalli, en coincidencia con la apariencia de estos objetos (que son como chimallis de barro).

Dos de los discos (un positivo y un molde) tienen, como hemos visto, la sucesión de crestas ondulantes alrededor de la flor. Si la flor es interpretada como herida abierta, el líquido aludido por las crestas sería sangre.

En los Cantares mexicanos encontramos claves importantes para advertir el simbolismo de la flor como metáfora del sacrificio. Uno de estos cantos, especialmente rico, es el Xopancuicatl de llamamiento a la guerra. ${ }^{50}$ Del campo de batalla se dice "allí están abriendo las flores [...] donde surge el agua divina, lo quemado (teoatl tlachinolli)"; ;I "en el lugar donde se adora a la aurora están abriendo las flores, en el lugar de la guerra florida de Tloque Nahuaque". ${ }^{2}$ Y además de hablar genéricamente de las flores, se alude expresamente al girasol: los nobles y valientes van a la guerra "Con su flor de escudo, con su flor de insignia de águila”. ${ }^{53} \mathrm{La}$ expresión utilizada para decir flor de escudo es,

50. Cantares mexicanos, fol. 6r y 6v. Mi traducción completa: Pablo Escalante Gonzalbo, "Xopancuícatl", La Gaceta del Fondo de Cultura Económica, núm. 231 (marzo 1990): 32-33. De allí proceden los fragmentos que cito.

5I. Teoatl tlachinolli es un difrasismo nahua para nombrar la guerra como asunto sagrado, la guerra como espacio de confrontación que emula el choque de los opuestos cósmicos, $v$. gr. agua vs. fuego. Los cautivos de guerra en general y los cautivos de la guerra sagrada especialmente, se convierten en víctimas sacrificiales. Las frases en náhuatl: "oncan ye oncuepontimania [...] oncan inemanaya oc teoatl tlachonollia".

52. "Tlahuizcalteochitla oncuepontimani yn ixochiquiyaopan in tloque in nahuaque".

53. "Chimalxochitl, quauhpilolxochitl yc". 
desde luego, chimalxóchitl, de manera que podría traducirse igualmente como "Con su girasol, con su insignia de águila".

De la flor surge un "néctar del color de la vida" ${ }^{54}$ Las últimas líneas del canto no dejan duda sobre su sentido sacrificial. Hablando del guerrero: "Buen canto, bella flor es su sangre, el líquido de su pecho". 55

En la Psalmodia christiana, ${ }^{56}$ una colección de cantos en lengua náhuatl elaborados por fray Bernardino de Sahagún y sus colaboradores indígenas, con la idea de reemplazar los cantos tradicionales indígenas por otros, de contenido evangélico, sacramental y de culto a los santos, se usa una terminología afín a la de los cantares y diversas metáforas que eran familiares a los nahuas y ahora debían aplicarse a la liturgia cristiana. Los cantos de la Psalmodia hablan en varias ocasiones de la sangre de Cristo, como era imprescindible que lo hicieran; la califican como preciosa con el término náhuatl tlaço: itlaçoezçotzi,57 su "sangre muy preciada y querida". También se refieren a cómo la Santa Cruz se embellece por la sangre de Cristo. ${ }^{58}$

La relación guerra/sacrificio, reiterada en la lírica nahua de origen antiguo, aparece también en el lenguaje de evangelización. Cuando en los salmos se habla del arcángel San Miguel se le nombra con un rango militar nahua tiacauh: in vei tiacauh, in vei Archangel, 59 el gran valiente, el gran arcángel. La muerte de Cristo en la cruz se describe asimismo como una batalla: "Una gran batalla, una gran guerra, se luchó; en la cruz Jesús luchó contra nuestros enemigos". ${ }^{60}$ Los términos usados para dicha batalla son los mismos empleados en la descripción de las guerras nahuas necaliliztli y yaoyotl.

Dos de los discos (un positivo y un molde) tienen como hemos visto la sucesión de crestas ondulantes alrededor de la flor, que parecerían reforzar el simbolismo de la sangre que brota de la "flor" abierta. Los otros dos discos muestran, en cambio, las volutas de humo propias de la ofrenda que se quema. ${ }^{6 \mathrm{I}}$ Esta

54. "Voliliztlapalneucxochitla".

55. "Vectli ya cuicatl, yectli ya xochitl ymeçoh ymelchiquiuhpatiuh", Cantares mexicanos, fol. $6 \mathrm{v}$.

56. Fray Bernardino de Sahagún, Psalmodia christiana, trad. Arthur J. O. Anderson (Salt Lake, Utah: University of Utah Press, 1993).

57. Sahagún, Psalmodia, 36.

58. Sahagún, Psalmodia, I48.

59. Sahagún, Psalmodia, 286.

6o. Sahagún, Psalmodia, salmos del segundo día de la fiesta de la Resurrección, p. I4.

6I. Códice Borgia, lám. 63. Sobre la transformación de la ofrenda por el fuego, Silvia Limón Olvera, El fuego sagrado. Simbolismo y ritualidad entre los nahuas (México: Universidad Nacional Autónoma de México, 20I2). 
ofrenda que se consume, para que pierda su materia pesada, se volatilice y pueda ser absorbida por los dioses, en la tradición mesoamericana, es en muchos casos una bola de zacate o papel impregnada de la sangre de un ave o de un sacerdote, también puede ser un corazón o la sangre de una víctima sacrificial. Así pues, en los cuatro discos se alude a la sucesión del hecho sacrificial: en dos de ellos por la sangre que fluye, en los otros dos por el humo que la eleva.

El sacrificio se expresa con símbolos de la tradición indígena (apertura de la flor, sangre, humo) y en un lenguaje metafórico tradicional indígena y nahua que estaba todavía en uso en el siglo xvI. Pero claramente, tanto las expresiones líricas como éstas en cerámica y cualesquiera otras estaban ya insertas en la vida ritual cristiana, eran parte de la liturgia cristiana. La presencia de la cruz confirma, por supuesto, el nuevo objeto del culto.

La cruz es evidente en el disco de la cruz, es la representación figurativa de los maderos de la cruz romana y se encuentra superpuesta al resto de los diseños. En el molde de las cuatro volutas es más sutil, está integrada al conjunto de los diseños: entre cada una de las vírgulas de humo surge una larga voluta en forma de $S$, cuatro en total, en ángulo recto, para formar la cruz. En el disco de los cuatro remates de plumas, lo que surge entre las vírgulas de humo son estos remates ornamentales, muy comunes en tocados, como los del Códice Borbónico. ${ }^{62}$

Hay una cuarta pieza, el molde de la mazorca de maíz, en el cual he argumentado la presencia de la chimalxóchitl abierta y el líquido ondulante. También está en este molde la sucesión de bandas en torzal, como las utilizadas en la tradición mesoamericana para expresar las vías de las fuerzas sagradas e idénticas a las del disco de la cruz latina. En el disco que habría de elaborarse con este molde no se advierte la forma de la cruz. No está. Lo que sí hay es un par de formas curvas que se abren hacia los lados, dejando emerger, en la parte superior, lo que parece ser una mazorca. Así lo sugieren su forma y el acompañamiento de las hojas que se abren. Y la verdad es que la mazorca de maíz sí tendría mucho sentido en los términos de la liturgia cristiano-indígena y de la analogía que caracterizó la construcción del discurso de evangelización, especialmente en las primeras décadas de relación entre franciscanos y pueblos nahuas.

Por muy difícil y comprometedor que pudiera haber sido enunciar frente a los indígenas el misterio de la transubstanciación, era indispensable hacerlo. De manera que a la vez que prohibían y combatían el sacrificio humano y la

62. Códice Borbónico (México: Siglo XXI, 198I), lám. I6. 
antropofagia, los frailes debían explicar a los indígenas que el pan y el vino se transformaban durante la misa en la carne y la sangre de Cristo, y luego eran ingeridos en la comunión. Y lo hicieron del mismo modo en que transmitieron las demás ideas, echando mano de la traducción y de la analogía.

En los cantos de la fiesta de Corpus Christi se entonaba: "Para fortalecernos, nos da a comer su precioso cuerpo, y para alegrarnos nos da a beber su preciosa sangre". ${ }^{63} \mathrm{Y}$ en el salmo contiguo se explica que aquello que ocurrió el Jueves Santo en Jerusalén lo realiza ahora la Santa Iglesia, cada día, en el momento de la consagración. Y qué es lo que ocurrió: in "tlascalli teunacatl omuchiuh: auh in vino, teueztli omuchiuh", "la tortilla se convirtió en carne divina y el vino se convirtió en sangre divina”. ${ }^{64}$

El maíz junto a la sangre, emergiendo de la flor, parece completar el mensaje cristológico del disco; prescinde de la cruz pero presenta el cuerpo y la sangre de Cristo. No está de sobra decir que las líneas utilizadas para sugerir los dientes de la mazorca, que son líneas más notables en la parte central, parecen formar una cruz, quizá en forma de Tau. Esto último, sin embargo, es una conjetura.

Habíamos mencionado un elemento que aparece en el disco de los cuatro ornamentos de pluma y en el molde de las cuatro volutas: una circunferencia formada por piezas iguales con forma de alargados trapecios. Su regularidad rectilínea sugiere que se trata de cuentas talladas, en realidad parece un sartal o un medallón extendido. Es importante observar que en ambos casos se trata de doce cuentas. El número doce no es significativo para la numerología mesoamericana; ${ }^{65}$ pero sí es muy importante en el cristianismo. En realidad, las cuentas y brazaletes aparecen en los mismos textos que venimos analizando, tanto en los cantos tradicionales nahuas de contenido sacrificial como en los salmos formados por Sahagún. En el Xopancuícatl se alude al campo de la guerra sagrada con la metáfora: "donde lloviznan cuentas del brazalete precioso". ${ }^{66}$

También en la Psalmodia aparecen metáforas asociadas al valor de las cuentas. La gracia del cristiano se compara con brazaletes y collares de jade que fueron dejados por los doce apóstoles al partir. ${ }^{67}$ También se incluye en un canto la figura de que la ciudad de Dios brilla como una estera de brazaletes

63. "Inic tito chicaoazque, otechmoqualtili in inacaiotzi:: aun inic tipapaquizque, otechmitili in itlaçoezçotzi”, Sahagún, Psalmodia, I72, cuarto salmo de Corpus Christi.

64. Sahagún, Psalmodia, I72, tercer salmo de Corpus Christi.

65. Como sí lo son el 2, el 4, el 5, el 9, el I3, el I8 o el 20.

66. "Ypixauhyan in nepapan tlaçomaquiztetl", Cantares mexicanos, fol. 6r.

67. Sahagún, Psalmodia, I8, prólogo, salmo segundo. 
y se dice que hay doce piedras preciosas en sus muros con los nombres de los doce apóstoles. ${ }^{68}$ Es posible, entonces, que el círculo de doce trapecios esté relacionado con el sacrificio y la gracia y que tenga un sentido apostólico.

\section{El tiempo y el lugar}

La colección de piezas, moldes y fragmentos procedentes de "la casa del alfarero" en Teotihuacán, que en su día adquirió Antonio Peñafiel y que actualmente guarda el Field Museum de Chicago parece haber formado parte de un proyecto decorativo para adornar algún pequeño recinto de culto, posiblemente la fachada de una capilla en ese mismo barrio de La Purificación, ${ }^{69}$ donde Peñafiel sitúa la evidencia de desplome y el hallazgo de las piezas.

La abundancia de moldes y su clara relación con las piezas indican que el material procede de un sitio de producción, de un taller de alfarería. La idea de que se trataba de "la casa" de un alfarero es fruto de una occidentalización de la mirada; para el medio indígena y especialmente en la etapa colonial temprana, parece más factible que se tratara de un taller de uso colectivo, e incluso es más probable que fuera del taller de una escuela de artes y oficios. ${ }^{70}$

La unidad en la técnica y los materiales, en la forma, las dimensiones y la iconografía corresponde con objetos que fueron producidos dentro de un breve lapso: no hay artefactos de diferentes épocas. La presencia de símbolos y temas explicables en términos de la tradición nahua del Posclásico es muy reveladora. Diversos motivos esquemáticos propios del repertorio del Posclásico como el glifo calendárico Nahui Ollin, el pictograma del plumón de garza, el pictograma de montańa o el caracol cortado coexisten con elementos de tipo naturalista, semejantes a los motivos ornamentales europeos que vemos en obras del siglo XVI, como los pájaros, algunas hojas y cenefas de flores.

Tal coexistencia es característica de las primeras cinco o seis décadas de la evangelización: no se habían olvidado los motivos prehispánicos y su simbolismo estaba aún parcialmente activo, interactuando con los nuevos símbolos

68. Sahagún, Psalmodia, I30, segundo y tercer salmos de Domingo de Pascua.

69. No es imposible que lo que en el siglo XIX es un barrio "de la Purificación" haya sido la ubicación del primitivo edificio de los franciscanos en la localidad.

70. Habría estado adjunta al antiguo "monasterio" de los franciscanos, cuya ubicación precisa desconocemos, o bien junto a una antigua capilla de barrio, antecedentes, en cualquier caso, de la pequeña iglesia próxima al predio de la que habla Peñafiel. Peñafiel, Teotihuacán, 50. 
y temas de origen europeo, tal como se aprecia en los Cantares y en la Psalmodia.

En la colección de "la casa del alfarero" hay muy poco que pudiéramos considerar inequívocamente precolombino (y mucho menos de la cultura teotihuacana). Tampoco hay indicios formales o iconográficos de intrusiones posteriores al siglo Xvi. En realidad, parece que estamos frente a las obras de un taller, montado quizá ex profeso para un proyecto: tal es la coherencia del material. Estos materiales parecen reflejar un solo momento, en el siglo xvi, que quedó sellado por el desplome de la construcción dentro de la cual se encontraban los moldes y las piezas.

Hay indicios para pensar que ese momento capturado por el desplome podría corresponder al lapso I557-I558. San Juan Teotihuacán había sido evangelizado por los franciscanos, como tantos otros pueblos del valle de México. Primero fue visita de Tetzcoco, pero al cabo de unos años, por razones de proximidad, el vínculo más estrecho fue con los franciscanos de Otumba. ${ }^{71}$ Incluso cuando a los agustinos se les asignó la visita de Teotihuacán, las autoridades de este pueblo siguieron manteniendo una relación preferente con los franciscanos y visitando Otumba, ${ }^{72}$ con la esperanza siempre de tener residiendo en su pueblo a los Hermanos Menores. ${ }^{73}$ En 1557 o acaso el año anterior —esto no es claro en las fuentes - los agustinos quedaron a cargo de San Juan Teotihuacán, y lo visitaban desde Acolman.

Los habitantes de San Juan Teotihuacán se resistieron a ver como permanente esta situación, nunca perdieron el vínculo con los franciscanos ni la esperanza de que éstos regresaran. Cuando, en 1557 , los agustinos decidieron construir

7I. Gerónimo de Mendieta, Historia eclesiástica indiana (México: Porrúa, 1980), lib. III, cap. LIX, 347-353; fray Juan de Torquemada, Monarquía indiana, coord. Miguel León Portilla, 7 vols. (México: Universidad Nacional Autónoma de México-Instituto de Investigaciones Históricas, I975-I983), lib. XIX, cap. VIII, vol. 6, 34-39; Peter Gerhard, Geografía histórica de la Nueva España, I519-I82I, trad. Stella Mastrangelo (México: Universidad Nacional Autónoma de MéxicoInstituto de Investigaciones Históricas, 1986), 282.

72. En particular, se dice que en Otumba los indios tenían "grande amor y respeto" por fray Juan de Romanones. Mendieta, Historia eclesiástica, 350; y durante el conflicto que a continuación se describe acudieron a misa en Otumba, $35 \mathrm{I}$.

73. Desde que les asignaron a frailes agustinos en sustitución de los franciscanos, empezaron a visitar a estos últimos, acudiendo incluso a México, y les "dijeron que no habían de parar hasta que les diesen lo que pedían. Y aunque los frailes de S. Francisco no los querían oír en el caso, no dejaban ellos de solicitar su negocio por todas las vías que podían”, Mendieta, Historia eclesiástica, 348 . 
un convento en San Juan Teotihuacán para tener allí una casa con frailes residentes, los habitantes se rebelaron. La rebelión se prolongó por dos años y es descrita con cierto detalle por fray Jerónimo de Mendieta (I525-I604). ${ }^{74}$ Intervinieron en el conflicto el alcalde mayor de Tetzcoco, el virrey, el arzobispo y un juez visitador; hubo azotes, ${ }^{75}$ sentencias a trabajos forzados y alguna batalla campal con enfrentamientos cuerpo a cuerpo entre gente del pueblo y enviados del arzobispo —incluido el juez visitador- que sólo concluyó cuando el encomendero, Alonso de Bazán, intervino con su espada desenvainada. ${ }^{76}$ Incluso hubo una noche en la que murió mucha gente ahogada, en medio de una tormenta, mientras trataban de huir. ${ }^{77}$

Según la descripción de Mendieta, el pueblo fue abandonado durante varios meses a lo largo de este tiempo de amotinamientos; táctica muy común entre los indios para eludir la represión de las autoridades coloniales. También sabemos, gracias a la descripción de Mendieta, que en San Juan había un "monasterio" anterior a la llegada de los agustinos y del que los agustinos quisieron apropiarse pintando en sus muros temas propios de su orden. ${ }^{78}$ Lo cual quiere decir que los franciscanos, aunque no tenían gente disponible para residir allí, habían dotado al pueblo de algo más que una capilla de visita.

En el relato del largo conflicto surge información relevante para el estudio de la colección de moldes y piezas que vengo examinando: se habla de diversos daños a la arquitectura y desplome de muros (aportillar, ${ }^{79}$ es el verbo que utilizan). Es probable que la arquitectura existente en Teotihuacán en aquellas fechas haya sido de adobe, y en todo caso no era muy sólida. Veamos.

En dos ocasiones las autoridades arrestaron e hicieron presos a algunos de los líderes indígenas de la comunidad: las dos veces los detenidos se fugaron

74. Mendieta, Historia eclesiástica, el citado capítulo LIX: "De lo que pasaron y padecieron los indios naturales de S. Juan Teutiuacan por tener doctrina de los frailes de S. Francisco", 347-353.

75. Los azotes comenzaron desde la primera negativa del pueblo a obedecer a los agustinos: el alcalde mayor de Tetzcoco, Jorge Cerón "mandó azotar públicamente en la plaza a todos los alguaciles", Mendieta, Historia eclesiástica, 348.

76. "con la espada desnuda por amedrentar a los indios los hizo arredrar", Mendieta, Historia eclesiástica, 349 .

77. "Murieron sesenta personas sin confesión, y veinte niños sin el agua del baptismo", Mendieta, Historia eclesiástica, 35I.

78. Los agustinos "mandaron luego pintar en la portería al santo patrón de su orden, y otro santo o santos de la misma orden, como por muestra de estar allí aposesionados, y ser aquel su monasterio", Mendieta, Historia eclesiástica, 348.

79. "Romper una muralla o pared" (RAE). 
tras romper una pared, y al menos en una de estas ocasiones es seguro que se encontraban en una dependencia del convento ${ }^{80}$ En algún momento, la gente descubrió que cinco o seis indígenas colaboradores de los agustinos estaban del lado de las autoridades y daban información sobre los planes del pueblo a los enviados del arzobispo. Es probable que se tratara de teopantlaca o "gente de la iglesia", ${ }^{81}$ algunos eran cantores y otros tenían cierta responsabilidad de llevar registro y cuidado de las cosas de la iglesia, como sacristanes. La reacción del pueblo fue golpearlos, expulsarlos de la comunidad y derrumbar sus casas. ${ }^{82}$

Pero la información más importante se refiere al convento mismo: cierta noche, cuando no había ninguna autoridad espańola en el pueblo y los agustinos tampoco estaban, la gente del pueblo aprovechó para llevarse el ajuar eclesiástico de valor: "acudieron la noche siguiente al monasterio" lo saquearon "sin dejar alguna cosa, salvo el monasterio aportillado". ${ }^{83}$ Los agustinos regresaron, y al ver "la casa tan mal parada, fueles forzado dar luego la vuelta" ${ }^{84}$ Fray Juan de Torquemada (I557?-1624), que cita el pasaje de Mendieta y glosa el episodio, se refiere a cómo "aportillaron" el monasterio, "sin dejar lugar de él que fuese de provecho para morarle o asistirle", y así los agustinos encontraron la casa "con tanta ruina" que tuvieron que regresar a Acolman. ${ }^{85}$

Por todo ello este episodio de abandono y destrucción me parece importante. La colección de moldes y piezas se conservó como un grupo homogéneo, sin alteraciones, sin irrupción de material posterior, quieta en el tiempo, reflejando un momento específico que fue el de la evangelización temprana, el de la política de sincretismo. ${ }^{86}$ Ese momento pudo haber sido justamente el de I557-I558. Tras el conflicto, los franciscanos volvieron a hacerse cargo del pueblo y eventualmente organizaron la construcción de un nuevo edificio. ${ }^{87}$

80. Mendieta, Historia eclesiástica, 349 .

8I. Categoría que incluía a los cantores pero también a sacristanes. Véase, al respecto, James Lockhart, The Nahuas After the Conquest. A Social and Cultural History of Central Mexico, Sixteenth Through Eighteenth Centuries (Stanford: Stanford University Press, 1992), 215-217.

82. Mendieta, Historia eclesiástica, 349.

83. Mendieta, Historia eclesiástica, 35I.

84. Mendieta, Historia eclesiástica, $35 \mathrm{I}$.

85. Torquemada, Monarquia indiana, 6, 37.

86. Pablo Escalante Gonzalbo, "El término sincretismo y el estudio del arte novohispano del siglo Xvi”, en Nombrar y explicar. La terminología en el estudio del arte ibérico y latinoamericano, 313.

87. Erigido oficialmente en doctrina franciscana en 1559, Gerhard, Geografía histórica, 282283. Se emitió una cédula real para que los indios de Teotihuacán no fueran forzados a recibir a religiosos de otra orden que no fuese de su agrado; además los recibió el virrey e instruyó al 
Tampoco es imposible que la colección fuese algunos años posterior a I557. En ese caso habría sido otro desplome el que explicaría que el material haya quedado atrapado. Por el momento, el lapso de los motines de I557-I558, es la mejor opción disponible.

\section{El campo de estudio del arte cristiano-indígena}

Por sugerencia de algunos lectores y dictaminadores de este trabajo, he decidido agregar unas líneas para referirme a antecedentes historiográficos que ayudan a acotar el campo de estudio al que pertenecen estas piezas de cerámica y en el cual se inscribe mi análisis.

Fue en la década de 1940 cuando por primera vez la historiografía del arte colonial se ocupó expresamente de los rasgos formales y de las peculiaridades ornamentales del arte elaborado por los artistas indígenas en el siglo XVI. El historiador José Moreno Villa tuvo el acierto de buscar un nombre para esas obras, para ese subestilo dentro de las manifestaciones del Renacimiento en la Nueva España: le llamó tequitqui. ${ }^{88}$ Identificar un grupo de obras y señalar los rasgos propios de la interpretación indígena fueron los grandes méritos de Moreno Villa. La definición que entonces ofreció y los casos que examinó corresponden básicamente con el bajorrelieve en piedra. En realidad el término tequitqui sigue vigente para describir ese tratamiento escultórico peculiar de las formas, más floridas y desordenadas, pero con una talla más plana (entre otros rasgos).

El siguiente paso en el estudio de las obras de mano indígena en el arte novohispano lo dio Manuel Toussaint, quien dedicó un capítulo de su Pintura colonial en México a lo que llamó "La pintura cristiano-indígena". ${ }^{89} \mathrm{El}$ uso de los dos términos, "cristiano" e "indígena”, unidos con un guión, apunta hacia uno de los rasgos más notables de este arte según lo conocemos hoy: la yuxtaposición. Es un arte en el que, como ocurre con los discos y otros materiales de cerámica de la colección Peñafiel, los elementos indígenas y los cristianos

provincial franciscano, fray Francisco de Toral para que enviara frailes que se hicieran cargo de la doctrina en el pueblo. Mendieta, Historia eclesiástica, 352.

88. José Moreno Villa, La escultura colonial mexicana (México: El Colegio de México, 1942). José Moreno Villa, Lo mexicano en las artes plásticas (México: El Colegio de México, 1948).

89. Manuel Toussaint, Pintura colonial en México (México: Universidad Nacional Autónoma de México-Instituto de Investigaciones Estéticas [1965], 2ª . ed. 1982), 23-33. 
aún pueden distinguirse, como componentes de dos tradiciones que se juntan, la cristiana y la indígena mesoamericana.

Elisa Vargaslugo continuó la reflexión sobre el fenómeno tequitqui, precisamente allí donde los rasgos descritos por Moreno Villa eran más apreciables: la talla indígena en piedra. ${ }^{\circ}$ Por su parte, Constantino Reyes Valerio se interesó en la descripción de Toussaint, aunque decidió invertir el orden de las palabras para honrar el protagonismo de la fuerza de trabajo indígena, y lo llamó "arte indocristiano". ${ }^{91}$ Fue especialmente meritorio el laborioso recuento que hizo Constantino Reyes de los elementos simbólicos de origen indígena presentes en el arte del siglo Xvi en los pueblos de indios.

Otra obra decisiva para la formación de este campo de estudio fue el libro de Jeanette F. Peterson, The Paradise Garden Murals of Malinalco, ${ }^{92}$ que además inauguraba el fuerte interés por estos temas que ha mostrado en los últimos años la historiografía estadounidense. El programa del claustro de Malinalco, con sus formas vegetales, los medallones con monogramas y, en general, la integración de las tradiciones ornamentales indígena y renacentista, es totalmente pertinente para una reflexión más amplia sobre los materiales de cerámica que aquí he presentado. En el interés y la investigación sobre Malinalco coincidió Jeanette con Isabel Estrada de Gerlero, quien ha realizado una de las más grandes contribuciones al arte del siglo Xvi en Nueva España. ${ }^{93}$

Sería muy largo para exponerlo aquí, pero es preciso añadir que el estudio sobre los códices pictográficos mesoamericanos, muchos de ellos de factura colonial, se ha ido vinculando cada vez más al estudio general del arte realizado por indígenas en la Nueva España. La obra pionera en el análisis de los códices como parte de ese proceso de transformación del arte indígena fue la de Donald Robertson. ${ }^{94}$ Toussaint incluyó algunos códices en su estudio del arte "cristiano-indígena", y Jeanette Peterson uso sistemáticamente el Códice florentino en el análisis de la pintura mural de Malinalco. El vínculo entre los temas,

90. Elisa Vargaslugo Rangel, Las portadas religiosas de México (México: Universidad Nacional Autónoma de México-Instituto de Investigaciones Estéticas, 1969).

9I. Constantino Reyes Valerio, Arte indocristiano. Escultura del siglo XVI en México (México: Instituto Nacional de Antropología e Historia, 1978).

92. Citado anteriormente, véase nota 36.

93. Elena Isabel Estrada de Gerlero, Muros, sargas y papeles. Imagen de lo sagrado y lo profano en el arte novohispano del siglo XVI (México: Universidad Nacional Autónoma de México, 20II).

94. Donald Robertson, Mexican Manuscript Painting of the Early Colonial Period. The Metropolitan Schools (New Haven: Yale University Press, 1959). 
las obras y los artistas de los códices y de las ornamentaciones conventuales me ha parecido relevante desde hace años. Recientemente hemos querido documentar un caso concreto, comparando dos obras pictóricas contemporáneas entre sí, de una misma comunidad, una sobre un muro y otra en un manuscrito, y el vínculo es claro. ${ }^{95}$

El día de hoy el campo de estudio se ha enriquecido notablemente. Entre las tareas pendientes se encuentra la vinculación de los trabajos antropológicos sobre la religiosidad indígena ${ }^{96}$ con las evidencias observables en las obras y fuentes del siglo Xvi. También se podría profundizar en el estudio de la conexión entre los hechos artísticos y la ideología y la cultura colonial, por vías como la que ha abierto Serge Gruzinski. ${ }^{97}$

\section{El estudio de la cerámica, y la cerámica colonial}

Hace tiempo que vengo reuniendo evidencia sobre la importancia de la cerámica en el arte conventual. El estudio de los discos que aquí se han examinado y de la colección Peñafiel en su conjunto es el inicio de un reconocimiento más extenso de la cerámica como otro factor de gran importancia, factor de continuidad y de cambio, sin duda, en el arte del siglo xvi. Entre los desafíos que tenemos para el estudio de la cerámica se encuentra el de conectar la reflexión sobre materiales novohispanos tempranos con obras y ejemplos prehispánicos. La colaboración entre historiadores del arte y arqueólogos será indispensable.

Además de las observaciones sobre técnicas de modelado y moldeado que hemos comenzado a hacer con varios materiales, es preciso incorporar el estudio de los hornos. Las investigaciones arqueológicas identifican la presencia de dos tipos de hornos en Mesoamérica, unos a ras de tierra y otros con pequeños pozos de hasta medio metro de profundidad, circulares u oblongos. ${ }^{98}$ Sería inte-

95. Pablo Escalante Gonzalbo y Aban Flores Morán, "Pintura mural y pintura de códices en Tepetlaoztoc a mediados del siglo xvi. Versatilidad de los artistas y comunicación de las formas y los temas", en Piedras y papeles, vestigios del pasado, ed. Raymundo Martínez García y Miguel Ángel Ruz Barrio, 77-9I (Zinacantepec: El Colegio Mexiquense, 20I7).

96. Como la obra ejemplar de Bricker, que ilumina algunos procesos no documentados en las fuentes tempranas. Victoria Reifler Bricker, The Indian Christ, the Indian King. The Historical Substrate of Maya Myth and Ritual (Austin: University of Texas Press, 1981).

97. Serge Gruzinski, La pensé métisse (París: Fayard, 1999).

98. Andrew K. Balkansky, Gary M. Feinman y Linda M. Nicholas, "Pottery Kilns of Ancient Ejutla, Oaxaca, Mexico", Journal of Field Archaeology, vol. 24, núm. 2 (verano, 1997): 129-I60. 
resante saber si los hornos empleados en las escuelas de artes y oficios conventuales seguían el mismo patrón de sus antecedentes prehispánicos. Por otra parte es posible que en estos contextos conventuales haya indicios de la génesis del horno de corriente ascendente (updraft kiln), que los arqueólogos identifican como una adquisición colonial.99

Algunos estudios pioneros en el tema de los hornos auguran buenas posibilidades para reconocer el cambio tecnológico colonial. Tal es el caso de las exploraciones en Tepeaca, Puebla, donde se han localizado decenas de hornos, tanto para cerámica como para cal, algunos prehispánicos y otros de diferentes etapas posteriores a la Conquista. ${ }^{100}$ Pero incluso sería factible aprovechar las estrategias de investigación que se han seguido con yacimientos netamente prehispánicos cuyos problemas presentan similitudes a los que enfrentamos en los vestigios novohispanos. Una característica destacada en la producción cerámica y en los hornos de algunas localidades antiguas es la alta especialización. ${ }^{\text {IOI }} Y$ precisamente un taller de alfarería como el nuestro, dedicado en exclusiva a la ornamentación de una capilla implica también una gran especialización. Incluso sería factible, en futuras excavaciones de espacios atriales, buscar indicadores de los procesos de colaboración en los talleres artesanales, tal como se han rastreado en contextos de origen prehispánico. ${ }^{\mathrm{IO} 2}$

En una etapa posterior al análisis del gran mosaico de la colección Peñafiel he propuesto el estudio de ladrillos y otras piezas de barro horneado realizadas ex profeso para formar capiteles, columnillas, molduras, y otros elementos empotrados en la arquitectura conventual. Para ello, parecen de gran utilidad los antecedentes de investigación en misiones de California y, en especial, las observaciones de los investigadores sobre la producción de teja y ladrillo. ${ }^{103} \mathrm{El}$ panorama es muy amplio, pero ya existen herramientas que pueden contri-

99. Gary M. Feinman y Andrew Balkansky, "Ceramic Firing in Ancient and Modern Oaxaca", en The Prehistory and History of Ceramic Kilns, ed. Prudence M. Rice (Westerville: The American Ceramic Society, 1997), 4II-420.

Ioo. Ronald A. Castanzo, "Tepeaca Kiln Project”, http://www.famsi.org/reports/0202I/ O2O2ICastanzoor.pdf, consultado el I de diciembre de 2017.

Ior. Robert S. Stanley, Philip J. Arnold y Christopher A. Pool, "The Ceramics Production System at Matacapan, Veracruz, Mexico”, Journal of Field Archaeology, vol. I6, núm. I (I989): I07-I32. I02. Rosemary A. Joyce, Julia A. Hendon y Jeanne Lopiparo, "Working With Clay", Ancient Mesoamerica, vol. 25, núm. 2 (otońo 20I4): 4II-42O.

I03. Julia G. Costello, "Brick and Tile Making in Spanish California with Related Old and New World Examples," en The Prehistory \& History of Ceramic Kilns, ed. Prudence M. Rice Ceramics Society (Westerville: The American Ceramic Society, 1997), 195-217. 
buir al estudio, aún incipiente, del uso de la cerámica en el arte conventual del siglo Xvi en la Nueva Espańa.

\section{Conclusiones}

El arte producido en los pueblos de indios de la Nueva Espańa y particularmente en sus conjuntos conventuales y capillas fue mucho más rico de lo que expresan hoy los edificios supervivientes. La plumaria, la orfebrería, la lapidaria, el arte en papel y madera continuaron siendo durante décadas componentes de la vida religiosa indígena.

En el caso de la cerámica, que vale la pena estudiar con mayor profundidad, encontramos dos vertientes que presentan problemas distintos. Por una parte, las obras fabricadas para su empotramiento en la arquitectura, como las molduras de las capillas-posas de Huaquechula, Puebla, o las gárgolas de la iglesia en ese mismo conjunto conventual. Y por otra parte los objetos de cerámica móviles: de gran tamaño, como las pilas bautismales, o mucho más pequeños, como las vasijas o las figuras de los belenes.

Las piezas de la colección Peñafiel se realizaron para decorar una superficie arquitectónica, probablemente una pequeña capilla, quizá una sacristía. Una pregunta que permanece necesariamente abierta se refiere a por qué este rico repertorio de piezas decorativas nunca se utilizó. En realidad, no estoy seguro de que haya sido así. Puede ser que algunas piezas similares a las que hoy vemos (incluso algunas surgidas de esos mismos moldes) hubieran salido del taller días o semanas antes del desplome para comenzar algún proyecto decorativo. La iglesia que actualmente existe en el barrio de la Purificación, en Teotihuacán, muestra bases, columnas, molduras y otros detalles que corresponden indudablemente a una iglesia franciscana del siglo XVI, aunque se le han hecho diversos añadidos y modificaciones. Sin embargo, no he visto en ella restos de ninguna decoración en cerámica similar a la que aquí analizamos. Lo cierto es que aquel taller cerámico sufrió un desplome que nos dejó una suerte de instantánea involuntaria de un día de producción. Ése es su gran valor. Es posible que el desplome mismo se explique por el estado de franca rebelión en el que vivió el pueblo por un tiempo, al que me he referido arriba.

Las obras del taller muestran un momento especial en la historia del arte y la cultura en México, lo que parece ser la primera etapa del proyecto de una liturgia sincrética y una vida bicultural en los pueblos de indios; un proyecto en el 
cual la Iglesia mantenía el control y conducía la educación, pero en el que se expresaban ampliamente las tradiciones visuales y simbólicas de origen mesoamericano. En ese momento puede apreciarse con claridad uno de los rasgos característicos del arte de la evangelización que es la yuxtaposición, una coexistencia de lo indígena y lo cristiano en la cual ambas tradiciones son aún visibles y no hay una mezcla que matice los orígenes hasta el punto de ocultarlos.

Nuestro conocimiento de la vida litúrgica y el arte cristiano-indígenas se completará en la medida en que integremos todos los géneros (plumaria, orfebrería, entre otros). También deberemos sumar en el conjunto aquellas obras no conservadas pero descritas o pintadas en los códices, y otras manifestaciones efímeras y orales. El conjunto de todas esas expresiones va mostrando un sistema coherente, hilvanado por las analogías. No hay fuente u objeto, por pequeño que sea, que no contribuya a la comprensión del universo simbólico de la vida religiosa indígena. s 